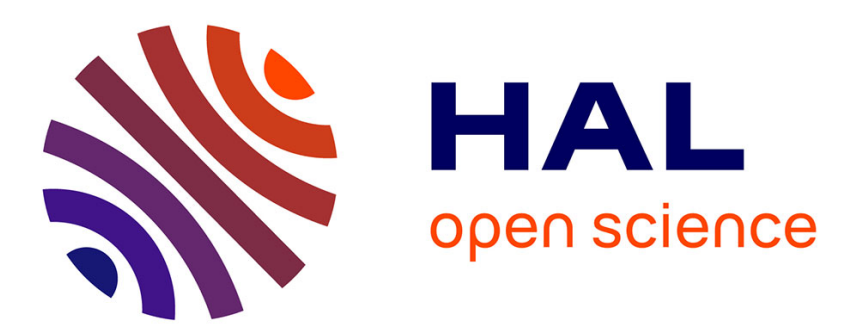

\title{
Reliability and prevalence of an atypical development of phonological skills in French-speaking dyslexics
}

\author{
Liliane Sprenger-Charolles, Pascale Colé, Agnès Kipffer-Piquard, Florence \\ Pinton, Catherine Billard
}

\section{To cite this version:}

Liliane Sprenger-Charolles, Pascale Colé, Agnès Kipffer-Piquard, Florence Pinton, Catherine Billard. Reliability and prevalence of an atypical development of phonological skills in French-speaking dyslexics. Reading and Writing, 2009, 22 (7), pp.811-842. 10.1007/s11145-008-9117-y . hal-00733554

\section{HAL Id: hal-00733554 \\ https://hal.science/hal-00733554}

Submitted on 1 Oct 2012

HAL is a multi-disciplinary open access archive for the deposit and dissemination of scientific research documents, whether they are published or not. The documents may come from teaching and research institutions in France or abroad, or from public or private research centers.
L'archive ouverte pluridisciplinaire HAL, est destinée au dépôt et à la diffusion de documents scientifiques de niveau recherche, publiés ou non, émanant des établissements d'enseignement et de recherche français ou étrangers, des laboratoires publics ou privés. 


\section{RELIABILITY AND PREVALENCE OF AN ATYPICAL DEVELOPMENT OF PHONOLOGICAL SKILLS IN FRENCH-SPEAKING DYSLEXICS}

\section{Reading and Writing, 22(7), 811-842}

Liliane Sprenger-Charolles ${ }^{\mathrm{a}}$, Pascale Colé ${ }^{\mathrm{a}-\mathrm{b}}$, Agnès Kipffer-Piquard ${ }^{\mathrm{c}}$, Florence Pinton ${ }^{\mathrm{d}}$, and Catherine Billard ${ }^{\mathrm{d}}$

${ }^{\mathrm{a}}$ CNRS-Laboratoire Psychologie de la Perception, Université Paris-Descartes, Paris; ${ }^{\mathrm{b}}$ Université de Savoie, CNRS-Laboratoire de Psychologie et Neurocognition; ${ }^{\circ}$ Université de Nancy, CNRS-Loria; ${ }^{\mathrm{d} C}$ Centre Hospitalier Universitaire de Bicêtre, Unité de Rééducation, Département de Pédiatrie

Address for correspondence: Liliane Sprenger-Charolles Laboratoire de Psychologie de la Perception

CNRS et Université Paris-Descartes, UFR Biomédicale des Saints Pères

45, rue des Sts Pères, 75270 Paris cedex 06

Tel: 33142864325

e mail: Liliane.Sprenger-Charolles@ univ-paris5.fr

Acknowledgments. This research was supported by a grant from the ACI 'Cognitique' (COG 129, French Ministry of Research). We would like to thank Danielle Béchennec, Isabelle Cannier-Olaogun, and Cecilia Vernerey-Ulucan for their help in collecting the data, and the reviewers for useful comments and corrections on earlier versions of this the paper. 


\begin{abstract}
In the present study, conducted with French-speaking children, we examined the reliability (group study) and the prevalence (multiple-case study) of dyslexics' phonological deficits in reading and reading-related skills in comparison with Reading Level (RL) controls. All dyslexics with no comorbidity problem schooled in a special institution for children with severe reading deficits were included in the study ( $\mathrm{N}=15$; Chronological Age [CA]: $111 \pm 8$ months; RL: $80 \pm 3$ months). For the group study, the 15 dyslexics were matched pairwise on reading level, non-verbal IQ, and gender to 15 younger RL controls (CA: $85 \pm 4$ months). For the multiple-case study, the RL control group included 86 average readers (CA: $83 \pm 4$ months; RL: $85 \pm 5$ months). To assess the relative efficiency of the sublexical (or phonological) and lexical reading procedures, we relied on two comparisons: pseudowords vs. high-frequency regular words (the comparison mainly used in languages with a shallow orthography); and pseudowords vs. high-frequency irregular words (the comparison mainly used with English-speaking dyslexics), pseudowords and irregular words being either short or long. The dyslexics' skills in the domains supposed to explain their reading deficit were also examined: phonemic awareness, phonological short-term memory and rapid naming. In the group study, the dyslexics lagged behind the RL controls only when they were required to read long pseudowords. The results of the multiple-case study indicated that the prevalence of this deficit was high (the accuracy scores of all but 2 of the 15 dyslexics being more than 1 SD below the RL control mean), and that deficits in phonemic awareness were more prevalent $(7$ cases) than deficits in phonological memory ( 1 case) and in rapid naming ( 2 cases). Three unexpected results were observed in the group study: the difference between regular words and pseudowords (to the detriment of pseudowords) was not greater for the dyslexics; the difference between irregular words and pseudowords (to the benefit of pseudowords) was more significant for the RL controls; and there were no significant differences between the groups in reading-related skills. To explain these results, the severity of the dyslexics' reading deficit and the remediation they have benefited from must be taken into account. In addition, the fact that the outcomes of the comparison between pseudoword vs. regular or irregular word reading were not the same will make it possible to understand some discrepancies between studies carried out either in English or in a language with a shallower orthography (French, for instance).
\end{abstract}

Key words: Dyslexia subtypes; Phonological dyslexia; Surface dyslexia; Lexicality effect; Length effect; Regularity effect; Phonemic awareness; Phonological short-term memory; Rapid naming; 


\section{$\underline{\text { INTRODUCTION }}$}

Developmental dyslexia refers to a developmental disorder, in contrast to acquired dyslexia, which is a disorder resulting from brain injury after the onset of reading. However, a child who has trouble learning to read is not always a dyslexic. Indeed, reading difficulties can have different origins, including mental retardation; visual or hearing impairment; poor mastery of the native language; inadequate educational opportunities; a penalizing social, cultural, or economic background; and emotional disturbances. It is only after the elimination of these potential causes of learning disabilities that it becomes possible to speak of developmental dyslexia.

Most studies on this developmental disorder have been based on the Coltheart's dual-route model which has been primarily developed to explain acquired dyslexia (Coltheart, Curtis, Atkins, \& Haller, 1993; Coltheart, Rastle, Perry, Langdon, \& Ziegler, 2001). According to this model, written words can be processed either by a lexical procedure (based on lexical units, such as words) or a sublexical procedure (based on sublexical units, such as Grapheme-Phoneme Correspondences, GPC). Dyslexics are assumed to suffer from a selective phonological deficit (in group studies), or to have a phonological profile (in single-case studies), when only their sublexical reading route is impaired. Alternatively, they are assumed to suffer from a selective visuo-orthographic deficit, or to have a surface profile, when only their lexical reading route is impaired. The efficiency of the sublexical reading route is mainly assessed by the reading of new words (pseudowords) that can be read using GPC. The efficiency of the lexical reading route is mainly assessed by the reading of well-known words, such as high frequency irregular words, that cannot be read using the sublexical procedure because they contain inconsistent GPC.

The results of group studies indicate that the main 'signature' of developmental dyslexia is a deficiency of the dyslexics' sublexical reading route, this deficiency being highly reliable and severe, at least according to studies with English-speaking dyslexics. Indeed, in most of the studies reviewed by Rack, Snowling and Olson (1992), for instance, dyslexics were found to lag behind younger children of the same reading level for pseudoword reading. However, such a difference between dyslexics and average readers may in fact be due to only some children in the sample. If so, it is illegitimate to assume that this deficit is prevalent.

Single-case studies have highlighted dissociated profiles, such as phonological profiles (e.g. in English: Snowling, Stackhouse, \& Rack, 1986; in French: Valdois, Bosse, Ans, Carbonnel, Zorman, David, \& Pellat, 2003) and surface profiles (e.g. in English: Coltheart, Masterson, Byng, Prior, \& Riddoch, 1983; in French: Valdois et al., 2003). However, a closer examination of these studies indicates that the surface dyslexics, for instance, also have deficient sublexical reading skills, as suggested by Bryant and Impey's (1986) reanalysis of the surface dyslexic described by Coltheart et al. (1983). These single-case studies suffer from two other limitations. First, only cases with dissociations between the lexical and the sublexical reading routes are emphasized, so that mixed profiles are never taken into account. Second, the prevalence of the different profiles is not examined. To access the prevalence of the various profiles, we underscore the importance of multiple-case studies that include dyslexics who have not been selected to fit a certain profile, i.e. all dyslexics should be eligible and their individual profiles then investigated. Like single-case studies, multiplecase studies examine individual cases, and like group studies, they look at a broad population assumed to be representative of the larger population of individuals with dyslexia. As such, they can assess the prevalence of the different profiles, whether dissociated profiles (phonological and surface profiles), or mixed profiles. Therefore, we have carried-out a multiple-case study, together with a group study.

In addition, one important finding in the current literature is that reading skills depend on GPC consistency (for reviews, see: Sprenger-Charolles, Colé, \& Serniclaes, 2006; Ziegler \& Goswami, 2005). Most studies on developmental dyslexia have in fact been conducted with English-speaking subjects. This poses a problem since, among the alphabetic scripts, English orthography is the deepest. Several cross-linguistic studies indicate that there are both similarities and differences in reading and reading-related skills between English- and German-speaking dyslexics, for instance (e.g. Landerl, Wimmer, \& Frith, 1997). So studies need to be conducted in languages with consistent GPC to examine which aspects of dyslexia depend on general principles, common to all languages, and which depend on the specific features of each language. We have therefore carried out a study in 
French, a language in which GPC are more consistent than in English (Peereman \& Content, 1998; Peereman, Lété, \& Sprenger-Charolles, 2007).

Finally, dyslexic children are only compared to same chronological-age average readers (CA) in some studies (e.g. Castles, Datta, Gayan, \& Olson, 1999). This poses two problems. On the one hand, since the paper by Bryant and Impey (1986) reading level has been known to have an impact on vocabulary size and phonemic awareness, for instance. Therefore, differences in these skills between dyslexics and CA controls may just be a consequence of the lower reading level of the dyslexics. On the other hand, there are processing trade-offs in the use of the sublexical and the lexical reading procedures that depend on the overall level of word recognition attained (e.g. for English-speaking children: Backman, Bruck, Hebert, \& Seidenberg, 1984; Waters, Seidenberg, \& Bruck, 1984; for French-speaking children: Sprenger-Charolles, Siegel, Béchennec, \& Serniclaes, 2003; SprengerCharolles, Siegel, \& Bonnet, 1998). To ascertain whether the reading system itself has developed differently in dyslexics, dyslexics have to be compared to same-reading-level (RL) controls. Therefore, we have carried-out a study involving dyslexics and RL controls.

The aim of the present study was to determine the origin of the differences between studies conducted in a language with either a deep or a shallower orthography. Its two first goals were to assess the reliability (group study) and the prevalence (multiple-case study) of the sublexical reading route deficit in French-speaking dyslexics. We used a RL match, and two comparisons: pseudoword reading was compared to regular word reading (the comparison mainly used in languages with a shallow orthography) and to irregular word reading (the comparison mainly used with Englishspeaking dyslexics). Its third and fourth goals were to assess the reliability (group study) and the prevalence (multiple-case study) of reading-related deficits in the main domains assumed to be impaired in dyslexics (phonemic awareness, phonological short-term memory, and rapid naming).

\section{SHORT REVIEW OF THE LITERATURE}

\section{Written-Word Processing in Developmental Dyslexia}

Both group studies and multiple-case studies have been mainly based on Coltheart's dual-route model (Coltheart et al., 1993, 2001). According to this model, written words can be read either by a lexical procedure (also called 'orthographic procedure') or by a sublexical procedure (also called 'phonological procedure'). In this framework, a lexicality effect (the superiority of words over pseudowords) is one of the indicators of the use of the lexical procedure since pseudowords have no address in the subject's internal lexicon. To read pseudowords, the reader must rely on the sublexical procedure. In alphabetic scripts, the sublexical written units (graphemes) must first be translated into the sublexical units of the spoken language (phonemes), and then 'assembled'. Reliance on the sublexical procedure is demonstrated by the presence of a regularity effect (the superiority of regular words over irregular words), for instance.

According to the literature, reliance on the sublexical procedure appears to be a bootstrapping mechanism for reading acquisition (Ehri, 1998; Share, 1995). If the quality of the lexical procedure depends on that of the sublexical procedure, and given that the dyslexics' sublexical reading skills are generally impaired (see Siegel, 1993; Stanovich, \& Siegel, 1994), then we can expect their lexical reading skills to be impaired as well. However, if the dyslexics' sublexical reading skills are more strongly impaired than their lexical reading skills, then their sublexical reading route deficit should be greater and should emerge even in comparison with RL controls. When such a disability is found, it means that the dyslexics' developmental trajectory is deviant.

\section{Results of Group Studies}

The results of studies carried out with English-speaking dyslexics indicate that their sublexical reading route deficit is highly reliable and severe. Indeed, in most of the studies reviewed by Rack et al. (1992), dyslexics were found to lag behind younger RL controls (e.g. Siegel \& Ryan, 1988; Snowling, 1981). However, in some studies such a deficit was not found (e.g. Szeszulski \& Manis, 1987). According to Rack et al., null results were mainly obtained in studies in which, on the one hand, dyslexics were matched with RL controls on the basis of connected-text reading or simple regular- 
word reading, and, on the other hand, when the pseudowords were simple. A meta-analytic review of the studies considered by Rack et al. (1992) was carried out by Van Ijzendoorn and Bus (1994). The main findings were that, first, a deficit in pseudoword reading was found in dyslexics compared to RL controls according to the combination of the results of the studies that, individually, did not find a significant group difference; second, the group difference was smaller in studies in which dyslexics were matched with RL controls on the basis of connected-text reading or simple regular-word reading; alternatively, the type of pseudowords used, especially their length (one versus more than one syllable), was not found to have an effect on the size of the group difference.

In addition, if the development of the lexical reading route depends on the efficiency of the sublexical reading route, and if a phonological deficit is at the core of developmental dyslexia, dyslexics' lexical reading skills must also be impaired. The main option for dyslexics would thus be to learn words by sight (or by heart). If this is true, they should show no strong advantage of regular words over irregular words. Indeed, the regularity effect provides an index of the subject's use of GPC to pronounce words. If dyslexics are less able to use this kind of knowledge, they should at the very least exhibit a smaller regularity effect than average readers. Despite the apparent validity of this prediction, according to the review by Metsala, Stanovich, and Brown (1998, mainly based on the studies reviewed by Van Ijzendoorn and Bus, 1994), a regularity effect of equal magnitude was observed for dyslexics and RL controls. Group studies therefore suggest that the dyslexics' reading impairment is primarily due to the weakness of their phonological reading skills, at least in English.

There are similarities and differences between studies conducted in languages with either a deep or a shallower orthography. Indeed, in English, as in German for instance, the main reading impairment found in dyslexics is primarily due the weakness of their sublexical reading skills (e.g. Landerl et al., 1997). However, this deficit mainly shows up in pseudoword reading accuracy scores in English (Rack et al., 1992; Van Ijzendoorn \& Bus, 1994). Alternatively, in transparent orthographies, this deficit mainly shows up in pseudoword reading speed (in Spanish: Jimenez-Gonzalez \& Valle, 2000; in French: Casalis, 1995; Grainger, Bouttevin, Truc, Bastien, \& Ziegler, 2003; Sprenger-Charolles, Colé, Lacert, \& Serniclaes, 2000).

The first goal of the present study was thus to determine the possible origin of these differences through a group study testing the reliability of the sublexical reading route deficit in French-speaking dyslexics. We used a RL match, and two comparisons: pseudoword reading was compared to regular word reading (the comparison mainly used in languages with a shallow orthography) and to irregular word reading (the comparison mainly used with English-speaking dyslexics). In addition, the length of pseudowords was manipulated, because some apparently inconsistent results on the length effect have been found, even in English (Rack et al., 1992; Van Ijzendoorn \& Bus, 1994). Finally, compared to the sample of a previous French study (Sprenger-Charolles et al., 2000), the dyslexics included in the present study were younger and more severely impaired, so that the trends observed in the previous study were expected to be replicated and reinforced. Especially, differences between dyslexics and RL controls were expected to be observed even in regard to accuracy scores, as in studies conducted with English-speaking dyslexics.

\section{$\underline{\text { Results of Multiple-Case Studies }}$}

One of the first investigators to have conducted multiple-case studies was Seymour (1986). More recently, five multiple-case studies were carried out, three with English-speaking dyslexics (Castles \& Coltheart, 1993; Manis, Seidenberg, Doi, McBride-Chang, \& Peterson, 1996; Stanovich, Siegel, \& Gottardo, 1997) ${ }^{1}$ and two with French-speaking dyslexics (Génard, Mousty, Content, Alegria, Leybaert, \& Morais, 1998; Sprenger-Charolles et al., 2000). Two methods were used to analyze the results: the classical method and the regression method. In the classical method, children are labeled 'phonological dyslexics' when only their sublexical reading route (assessed via pseudoword reading) is impaired, and 'surface dyslexics' when only their lexical reading route (assessed via high-frequency irregular-word reading) is impaired; when both routes are deficient, they are said to have a 'mixed profile' or a 'double deficit'. In contrast to the classical method, the regression method points to a relative deficit, either in the orthographic skills of dyslexics relative to their phonological reading skills, or in their phonological reading skills relative to their orthographic skills. Stanovich et al. (1997) characterized the subtypes defined in this manner as 'soft', as opposed to the 'hard' subtypes 
defined using the classical method. Soft subtypes are defined by plotting pseudoword performance against irregular-word performance (and vice versa) and then examining the 90\% (or 95\%) confidence intervals around the regression lines determined from the control group. A phonological dyslexic is a child who is an outlier when pseudowords are plotted against irregular words but who is in the normal range when irregular words are plotted against pseudowords. Surface dyslexics are defined in the opposite fashion. Dyslexics whose scores are outside the confidence intervals in both cases have a mixed profile. In all but one these studies, the sole indicator of reading efficiency was accuracy; in one study, correct-response latency was also taken into account (Sprenger-Charolles et al., 2000).

If the quality of the lexical procedure depends on that of the sublexical procedure, and given that the dyslexics' sublexical reading skills are generally impaired, then we can expect their lexical reading skills to be impaired as well. Therefore, we should not find dissociated profiles in dyslexia, at least in comparison with CA controls. However, if the dyslexics' sublexical reading skills are more strongly impaired than their lexical reading skills, only phonological profiles should be found in developmental dyslexia, at least in comparison with RL controls.

For the CA comparison, in the accuracy-based English studies, the classical method revealed a low percentage of hard-dissociated profiles and a high percentage of mixed profiles. In addition, the proportion of hard phonological and surface dyslexics was consistently across studies almost the same (15\% vs. $17 \%$ in Castles \& Coltheart, 1993; $9 \%$ vs. $12 \%$ in Stanovich et al., 1997; 10\% in both cases in Manis et al., 1996). A similar result was observed in the latency-based French study (16\% vs. 19\%, respectively, in Sprenger-Charolles et al., 2000), but not in the accuracy-based French studies, where the percentage of hard phonological dyslexics was found to be lower than that of hard surface dyslexics (3\% vs. $23 \%$ in Génard et al., 1998; $10 \%$ vs. $19 \%$ in Sprenger-Charolles et al., 2000).

Because of ceiling effects on irregular-word accuracy in CA controls, the regression method was used only for correct-response latencies in one study (Sprenger-Charolles et al., 2000). In sharp contrast with the results obtained with the classical method, the regression method pointed out a high percentage of soft-dissociated profiles, and a low percentage of mixed profiles. However, the proportion of the soft-dissociated profiles was highly inconsistent, even within a given language. Indeed, in the accuracy-based English studies, soft phonological profiles were either more prevalent than soft surface profiles (55\% vs. 30\%, Castles \& Coltheart, 1993), or almost equally prevalent (33\% vs. $29 \%$, Manis et al., 1996; $25 \%$ vs. $22 \%$, Stanovich et al., 1997). In French, results varied depending on the measure used: in the accuracy-based study, soft phonological profiles were the least prevalent (4\% vs. 56\%, Génard et al., 1998) whereas, in the latency-based study, soft phonological profiles were the most prevalent (52\% vs. 32\%, Sprenger-Charolles et al., 2000).

For the RL comparison, only the data from the regression method were used because the number of hard profiles found with the classical method was too low. Among English dyslexics, the proportion of soft phonological profiles was high (38\% in Castles \& Coltheart according to Stanovich et al.'s 1997 analyzes; 29\% in Manis et al., 1996; 25\% in Stanovich et al., 1997), and the proportion of soft surface profiles was low (1 to 5\%). Among French dyslexics, the proportion of soft phonological profiles was also higher than that of soft surface profiles: $39 \%$ vs. $10 \%$ in the latency-based study (Sprenger-Charolles et al., 2000), 8\% vs. 0\% in the accuracy-based study (Génard et al., 1998).

The prevalence of the different profiles seems thus to depend on the language (English vs. French), on the measure used to classify dyslexics (accuracy vs. speed), on the comparison (CA vs. RL controls), and on the method used to establish their profile (classical vs. regression-based method). Above all, first, the proportions of soft-dissociated profiles varied noticeably even according to a single measure within a given language (see the results of the accuracy-based English studies), in contrast to the proportion of hard-dissociated profiles. The regression method is thus less robust than the classical method. Second, the results of the accuracy-based English studies were more similar to those of the latency-based French study than to those of the accuracy-based French study.

The second goal of the study was thus to determine the origin of these differences, through the assessment of the prevalence of the different profiles in French-speaking dyslexics. A multi-case study was thus conducted comparing the reading scores of each of the dyslexics incorporated in the group study to those of a RL control group. The classification was based on the classical method, because that method is more robust than the regression method. As for the group study, pseudoword reading was compared to regular word reading and to irregular words reading. Compared to a 
previous French study's sample (Sprenger-Charolles et al., 2000), the dyslexics in this new sample were younger and more severely impaired, so that we expected to find more phonological than surface profiles, even with regard to accuracy scores, as in studies conducted with English dyslexics.

\section{$\underline{\text { Reading-Related Skills }}$}

The difficulties experienced by dyslexics in reading new words are generally explained in terms of their poor phonological skills outside the reading domain, especially in phonemic awareness and in phonological short-term memory. These deficits may hinder the proper acquisition of the sublexical reading procedure since it requires the ability to connect sublexical writing units (graphemes) to their corresponding sublexical speaking units (phonemes), and then to assemble together the units that result from the phonemic decoding process. The first operation requires fully-established phonemic categories; the second, adequate phonological short-term memory. A child who is unable to correctly handle phonemes, and who in addition suffers from a deficit in phonological short-term memory, will scarcely be able to use a sublexical reading procedure. Thus, developmental dyslexia may be rooted in a specific cognitive deficit that is phonological in nature. More recently, it has been assumed that there are two independent sources of reading dysfunction, one related to phonological processing (usually assessed by accuracy scores on phonological awareness and on phonological short-term memory tasks), the other related to lexical access (usually assessed by processing speed in the rapid automatic naming of highly frequent items or RAN). Two types of evidence have been presented in support of the double deficit hypothesis (see Wolf, Goldberg O'Rourke, Gidney, Lovett, Cirino, \& Morris, 2002; but see Vellutino, Fletcher, Snowling, \& Scanlon, 2004; Vukovic \& Siegel, 2006; Wagner, Torgesen, Rashotte, Hecht, Barker, Burgess, Donahue, \& Baron, 1997). First, RAN tasks have been found to explain the unique variance in reading beyond that explained by phonological awareness. Second, phonological awareness and rapid naming has been found to be related differentially to reading skills, the former to pseudoword accuracy scores and the latter to processing speed and/or word accuracy scores.

The main findings of the research in regard to reading-related skills were that, first, in the comparison with RL controls, deficits in phonemic awareness have been found to be more reliable than deficits in phonological short-term memory or in rapid naming (e.g. in English: Bruck, 1992; Chiappe, Stringer, Siegel, \& Stanovich, 2002; Pennington, Cardoso-Martins, Green, \& Lefly, 2001; in German: Wimmer, 1993). Second, some discrepancies between the results of dyslexics faced with a transparent orthography have been reported in regard to phonemic awareness. Indeed, such a deficit was observed in some studies (e.g. Spanish: Jimenez-Gonzalez, \& Ramirez-Santana, 2002; Czech: Caravolas, Volin, \& Hulme, 2005; German: Landerl et al., 1997; Wimmer, 1993) but not in other studies (e.g. Landerl \& Wimmer, 2000). Finally, contradictory findings about the presence of these phonological deficits in phonological and surface profiles have been reported. Indeed, in some studies phonological dyslexics alone were found to suffer from phonological deficits (e.g. in English: Manis et al., 1996; Stanovich et al., 1997), but not in other studies (e.g. in English: Zabell \& Everatt, 2002; in Spanish: Jimenez-Gonzalez, \& Ramirez-Santana, 2002; in French: Sprenger-Charolles et al., 2000).

These results point out the need for studies with non-English-speaking dyslexics. The third and fourth goals of the study were thus to assess the reliability (group study) and the prevalence (multiplecase study) of the reading-related deficits in French-speaking dyslexics compared to RL controls.

\section{OVERVIEW OF THE PRESENT STUDY}

The present study was conducted with French-speaking children. We examined the reliability (group study) and the prevalence (multiple-case study) of dyslexics' deficits in reading and in reading-related skills, in comparison with RL controls. For the multiple-case study we used the classical method, because this method appears to be more robust than the regression based method, results across studies being more consistent with the former than with the latter method. To assess the relative efficiency of the lexical and sublexical procedures, we relied on two main comparisons in readingaloud tasks: high-frequency regular words vs. pseudowords (the comparison mainly used in languages with a shallow orthography); short and long high-frequency irregular words vs. short and long 
pseudowords (the comparison mainly used with English-speaking dyslexics). The performance of the dyslexics in the domains supposed to explain their reading deficit was also examined: phonemic awareness, phonological short-term memory and rapid naming.

Compared to a previous French study's sample (Sprenger-Charolles et al., 2000), the dyslexics in this new sample were younger and more severely impaired (they were recruited from a special institution whereas the dyslexics in the previous study were recruited in normal schools). Given the younger age and the stronger severity of the reading impairment of the new dyslexic sample, the trends observed in the previous French study were expected to be replicated and reinforced. Especially, differences between dyslexics and RL controls were expected to be observed even in regard to pseudoword accuracy scores, at least for difficult pseudowords such as long pseudowords, this deficit being expected to be prevalent. In the reading-related tasks, the scores of the dyslexics were expected to lag behind those of the RL controls, but the difference between the two groups was expected to be less noticeable for phonological short-term memory and rapid naming than for phonemic awareness.

\section{EXPERIMENTS}

\section{METHOD FOR THE GROUP AND MULTIPLE-CASE STUDIES}

\section{Participants}

The group of dyslexics included all the dyslexics with a reading age of $7(\mathrm{~N}=15$; mean chronological age in months: 111, SD: 8) schooled in a special institution for children with extremely severe language or reading impairments. This special center is located in a hospital in the Paris area. The staff includes neuro-pediatricians, speech therapists, psychologists, and teachers. Each year, nearly 1000 out-patient children suffering from language or reading disorders arrive at this special center for a medical consultation. Only the most severe cases (those who remained severely impaired readers in spite of individual trainings by a speech therapist) are enrolled in the center's school, for one or two years (30 to 40 inpatients per year). During the 2002-2003 school year, there were 36 children at the center. According to the neuro-pediatricians' diagnoses, 11 were suffering from specific language impairment, 2 from Landau-Kleffner Syndrome, and 23 from dyslexia. Of the 23 dyslexics, 6 were not eligible for the study, 4 because they were not native French speakers and 2 because of a non-specific reading disorder. Finally, 2 children left the institution during the assessment period. The 15 remaining dyslexics had no cognitive deficits, whether verbal (assessed by the TVAP, Deltour \& Hupkens, 1980 or by the EVIP, Dunn, Thériault-Whalen, \& Dunn, 1993), or non-verbal (assessed by the RAVEN matrices, 1947/1981). Eight were new to the school, while the seven others had already attended this institution during the 2001-2002 school year ${ }^{2}$.

For the group study, the 15 dyslexics were matched pairwise to 15 controls on reading level, nonverbal IQ and gender (see Table 1 and Appendix A). According to a standardized test ('Alouette', Lefavrais, 1967), the mean reading level was exactly the same for the two groups (mean reading level in months: 80, SD: 3 ), but the dyslexics were older than the RL controls (mean CA in months: 111 vs. 85 , SD: 8 vs. 4). The children from the control group were selected among a large cohort of 100 first graders (Sprenger-Charolles, Colé, Béchennec, \& Kipffer-Piquard, 2005). For the multiple-case study, we used the normative data from this cohort. More precisely, among the 100 first graders, 14 children were classified as above-average readers, and 86 as average readers. To enable comparison between dyslexics and readers who showed normal reading performance, only the average readers were included in the control group, as in the study of Sprenger-Charolles et al (2000). These children were native French speakers without language or sensori-motor impairments and without psychological problems. They had no cognitive deficits, whether verbal (assessed by the TVAP, Deltour \& Hupkens, 1980) or non-verbal (assessed by the RAVEN matrices, 1947/1981) and were in the normal grade for their age. The descriptive data are presented in Table 1 and Appendix A. 
Table 1. Characteristics of the Dyslexics and RL Controls (Group and Multiple-Case Studies).

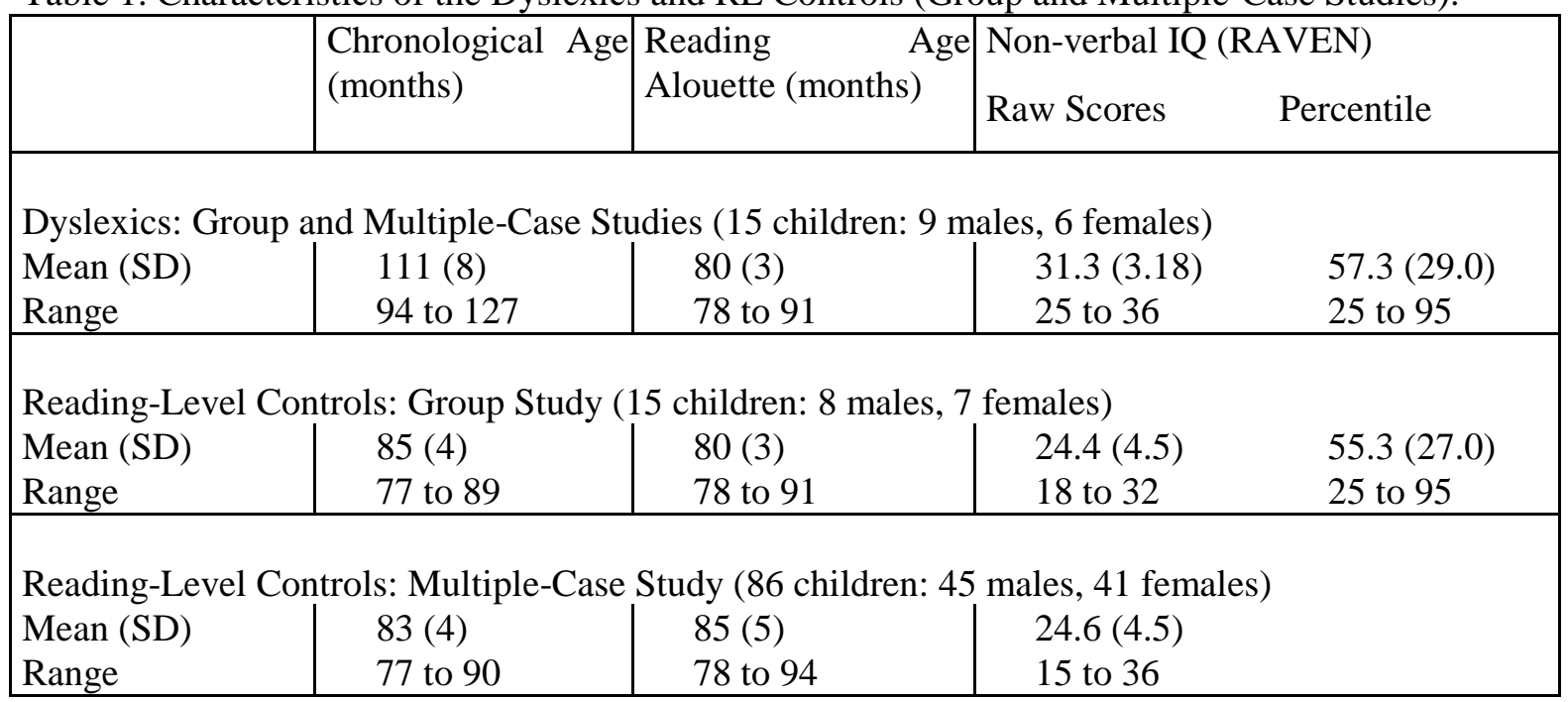

\section{Tasks and Procedures}

\section{Reading level: 'Alouette' test (Lefavrais, 1967)}

The participants were required to read aloud a 265 -word text as rapidly and as accurately as possible. The text included rare words and a lot of misleading contextual information (for example, after 'lac' [lake], 'poison' [poison] rather than 'poisson' [fish]). Therefore, this test prevented the biases mentioned by Rack et al. (1992), especially because dyslexics and poor readers rely more strongly on contextual information than average readers. The score was based on the reading time if the text was read in less than 3 minutes or on the number of words read in 3 minutes if not, minus 1 point per error in both cases.

\section{Written word processing: EVALEC (Sprenger-Charolles et al., 2005)}

The EVALEC reading tests are computerized tests for assessing various reading skills in reading aloud and in silent reading. For the reading-aloud tasks (LEVORT, LEXORT, LEXLENGTH, see explanation below), the children's vocal responses were recorded. This allowed us to check for the correctness of the responses, and to determine the beginning of the production for each correct response by way of a speech signal analysis. The children were instructed to respond as accurately and as quickly as possible but to not pronounce the word until they had read it completely. Practice items were used to ensure that the instructions were understood. For pseudowords, we specified that the task dealt with 'alien' words. The pseudoword reading tasks were presented after the word reading tasks.

The aim of the LEVORT test is to assess the efficiency of the lexical procedure (and the effect of regularity). This test contains 48 frequent words from four levels of regularity (12 items per level), regular words with only simple graphemes (R1: one letter per phoneme), regular words with a phoneme whose written form is a digraph (R2: 'ch'/S/; 'ou' /u/, etc.), regular words with a grapheme whose pronunciation depends on the context (R3: 'c'/k/ or /s/; 'g'/g/ or /Z/, etc.) and irregular words (R4: with either a silent grapheme, e.g. 'sept'/set/, or a grapheme with an exceptional pronunciation, e.g. the 'e' in 'femme', which is pronounced /a/). The items at each of the 4 levels are matched in length (number of letters, phonemes, and syllables), bigram frequency (Content \& Radeau, 1988), lexical frequency (MANULEX, Lété, Sprenger-Charolles, \& Colé, 2004), and word-initial phoneme.

The LEXORT and LEXLENGTH tests assess the efficiency of the lexical procedure as compared to the sublexical procedure (and the effect of lexicality). The lists contain high-frequency regular words and pseudowords matched on orthographic complexity (LEXORT) or high-frequency irregular words and pseudowords matched on length (LEXLENGTH). LEXORT uses words from LEVORT's first three levels of regularity, and pseudowords based on the same principle (R1: 'tomate'-'pitode'; R2: 'malin'-'nurin'; R3: 'cinéma'-'cirate', 12 items per category). LEXLENGTH uses 20 high- 
frequency irregular words and 20 pseudowords, 10 short and 10 long (4 vs. 8 letters, e.g. 'écho''opha' vs. 'orchestre'-'orphade'). The LEXORT and LEXLENGTH items were matched on the same criteria as in the first test.

The silent reading test is in an orthographic choice test. Its aim is to assess the efficiency of the lexical procedure in a silent reading task by taking into account the accuracy and speed of detection of a frequent word presented with a pseudo-homophone and a visual foil (9 items). The pseudohomophones sound like the correct word but have one letter more or less. The visual foils have the same number of letters as the target word with which they share a strong visual resemblance. A font was specially designed for this purpose. For example, the letter ' $a$ ' was represented by ' $a$ ', so that the shapes of the visual foils (outo, troin) were closer to those of the correct words (auto, train) than were those of the phonological foils (oto, trin). The mean trigram frequency in the two types of foils was similar (Content \& Radeau, 1988). The correct word and the two foils in each triplet were presented on the same line, in random order. The children were asked to choose the correct word by pressing a key on the computer keyboard. Practice items were used to ensure that the children understood the instructions.

\section{Phonemic awareness, phonological short-term memory, and rapid naming tests}

To assess phonemic awareness and short-term memory, EVALEC (Sprenger-Charolles et al., 2005) uses pseudowords in order to avoid biases due to differences in the children's vocabulary level. In addition, to avoid differences in experimenter's articulation, the items were recorded beforehand and the children heard them through headphones.

The phonemic awareness test included 3-phoneme pseudowords, 12 with a consonant-vowelconsonant (CVC) structure, and 12 with a consonant-consonant-vowel (CCV) structure. For the CVC test, the initial consonant was either a plosive or a fricative (half of each). For the CCV test, a plosive (4 items) or a fricative (4 items) was followed by a liquid and a plosive was either followed ( 2 items) or preceded ( 2 items) by a fricative. The children were instructed to 'eat' the beginning of 'alien' words on practice items. No feedback was given during the test. The CVC task was followed by the CCV task.

To assess phonological short-term memory, we designed a list of 3- to 6-syllable pseudowords (6 items for each length, 3 with only CV syllables and 3 with a CVC syllable). The items were presented one at a time, in increasing order of length (the six 3-syllable items first, followed by the 4-, 5-, and 6syllable items). The children were required to repeat each item as accurately as possible, with no time constraint. The memory span measure was the number of syllables in the items of the last series for which at least four correct responses were given. Practice items were provided and no feedback was given during the test.

Naming speed was assessed by a serial naming task using color names because the ability to name colors is assumed to be less dependent on reading level than the ability to name letters or digits (Parrila, Kirby, \& McQuarrie, 2004; Wagner et al., 1997). The children were required to name six colors presented 8 times in a different order, as rapidly and as accurately as possible. Three items had a CVC structure: 'rouge' (red), 'jaune' (yellow), 'vert' (green), and three items had a CCV structure: 'bleu' (blue), 'blanc' (white), 'gris' (grey). Before the test, the child was shown the 6 colored dots and asked to name them. In case of an error, the examiner gave the correct answer and made sure that the child had understood. The items were presented on a sheet of paper.

\section{RESULTS OF THE GROUP STUDY}

The main assumption was that only phonological deficits would be found in the comparison between dyslexics and RL controls. Therefore, differences between the groups would be observed only for pseudoword reading (Hypothesis 1), especially for difficult items such as long pseudowords (Hypothesis 2). In addition, the effect of lexicality on performance would be more noticeable for dyslexics than for average readers (Hypothesis 3), but not the effect of regularity (Hypothesis 4). In the reading-related tasks, the scores of the dyslexics were expected to lag behind those of the RL 
controls (Hypothesis 5), but the difference between the two groups was expected to be less noticeable for phonological short-term memory and rapid naming than for phonemic awareness (Hypothesis 6).

\section{$\underline{\text { Reading Tasks }}$}

To assess the efficiency of the lexical procedure (and the effect of regularity), we used the LEVORT test and the orthographic choice task. To compare the efficiency of the lexical and sublexical procedures (and the effect of lexicality), we used the high-frequency regular words vs. the pseudowords from the LEXORT test, and the high-frequency short and long irregular words vs. the pseudowords from the LEXLENGTH test. Only accuracy scores were examined since the accuracy level of most of the children was too low to allow us to use the latency data. For example, the regularity effect could be assessed only for the 4 children (out of 15 in each group) who correctly read at least $50 \%$ of the irregular LEVORT words. For the lexicality effect, only 7 RL controls and 6 dyslexic children read more than $50 \%$ of the LEXORT pseudowords, and only 2 dyslexics (vs. 8 controls) reached 50\% correct responses for the long LEXLENGTH pseudowords.

\section{Word reading (LEVORT)}

The results are presented in Figure 1. An ANOVA was run with the group factor (a 2-level betweensubject factor: 15 dyslexics and 15 RL controls) and the orthography factor (a 4-level within-subject factor). When the orthography effect was significant, we assessed the regularity effect (comparison between the R1, R2, and R3 regular words vs. the R4 irregular words). As expected, the main group effect was not significant $(\underline{F}<1)$, whereas a significant effect was found for the orthography factor $(\underline{F}(3-84)=63.94, \underline{p}<0.0001)$, due to the superiority of regular words over irregular ones $(+36.5 \%, F(1-$ $28)=98.1, \mathrm{p}<0.0001)$. The group by orthography interaction was not significant $(\underline{F}(3-84)=1.16)$, and the regularity effect was of equal magnitude for dyslexics and RL controls $(\underline{F}(1-14)=59.8, \underline{p}<0.0001$ for the dyslexics and $\underline{F}(1-14)=44.0, \underline{p}<0.00025$ for the RL controls), as in most previous studies.

\section{Word versus pseudoword reading (LEXORT and LEXLENGTH)}

For the LEXORT task, the results are presented in Figure 1. An ANOVA was conducted on the group factor (2 levels) and the lexicality factor (2 levels: regular word vs. pseudoword). The lexicality effect was significant (words were $21 \%$ more likely to be read correctly than pseudowords, $\underline{F}(1-28)=38.89$, $\underline{\mathrm{p}}<0.0001)$, but the group effect and the group by lexicality interaction were not $(\underline{F}<1)$. Thus, contrary to our hypotheses, the lexicality effect was not stronger for the dyslexics (Hypothesis 3) and their performance on pseudowords was commensurate with that of the RL controls (Hypothesis 1).

The results for the LEXLENGTH task are presented in Figure 2. An ANOVA was conducted for the group ( 2 levels), lexicality ( 2 levels: irregular word vs. pseudoword) and length ( 2 levels) factors. The lexicality effect was significant $(\underline{\mathrm{F}}(1-28)=58.61, \underline{\mathrm{p}}<0.0001)$. However, unlike in the preceding analyses, the words - here, irregular - were read less well than the pseudowords $(-27.2 \%)$. The length effect was also significant $(\underline{\mathrm{F}}(1-28)=54.66$, $\mathrm{p}<0.0001)$, with short items being read more accurately than long ones. The group effect and the three-way interaction were nonsignificant $(\underline{F}(1-28)=1.39$ and $1.0)$, whereas the group by lexicality and the lexicality by length interactions were significant $(\underline{\mathrm{F}}(1-$ $28)=7.17, \underline{p}<0.025$ and $\underline{F}(1-28)=27.81, \underline{p}<0.00025$, respectively). Compared to RL controls, the scores of the dyslexics were not significantly higher for irregular words $(+2.3 \%, \underline{\mathrm{F}}<1)$, whereas they were significantly lower for pseudowords $(-16.7 \%, \underline{F}(1.28)=4.42, \mathrm{p}<.05)$. These results fit with Hypothesis 1. Yet, contrary to Hypothesis 3, the lexicality effect was more noticeable for the RL controls $(+36.7 \%$, to the benefit of pseudowords) than for the dyslexics $(+17.7 \%$, also to the benefit of pseudowords). The lexicality by length interaction was due to the item-length effect being more marked for pseudowords (lag between short and long pseudowords, 29.3\%), than for irregular words (3.0\%). Finally, the dyslexics scored significantly lower than the RL controls only for long pseudowords $(-22.7 \%, \underline{F}(1-28)=8.68, \underline{p}<0.01)$, not for short pseudowords $(-10.7 \%, \underline{F}=1.38)$, which supports Hypothesis 2. 
Figure 1. Mean Percentage (and SD) of Correct Responses on Word Reading (LEVORT) and on Regular Word versus Pseudoword Reading (LEXORT)

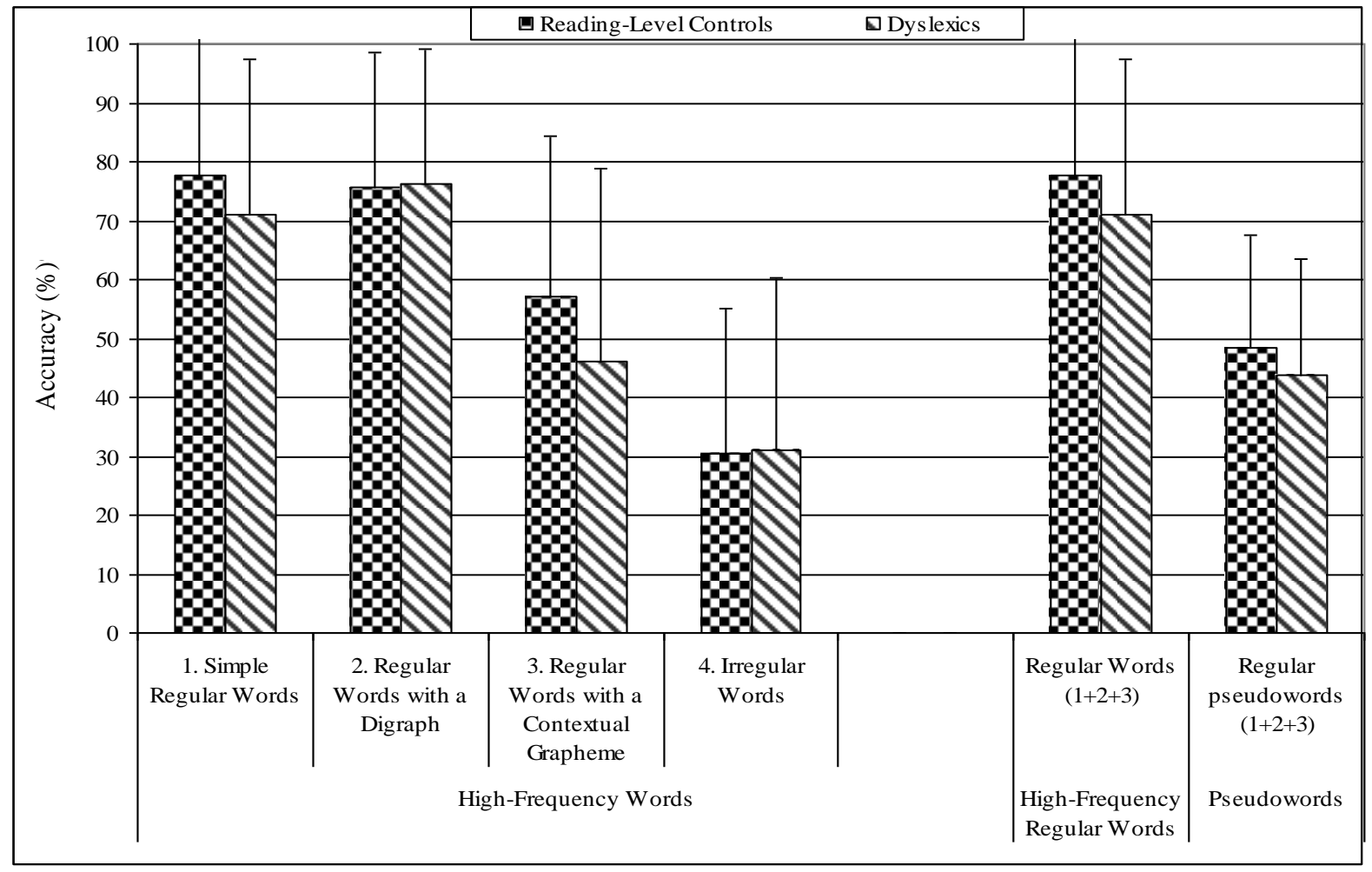

Figure 2. Mean Percentage (and SD) of Correct Responses on High-Frequency Short and Long Irregular Words and Short and Long Pseudowords (LEXLENGTH)

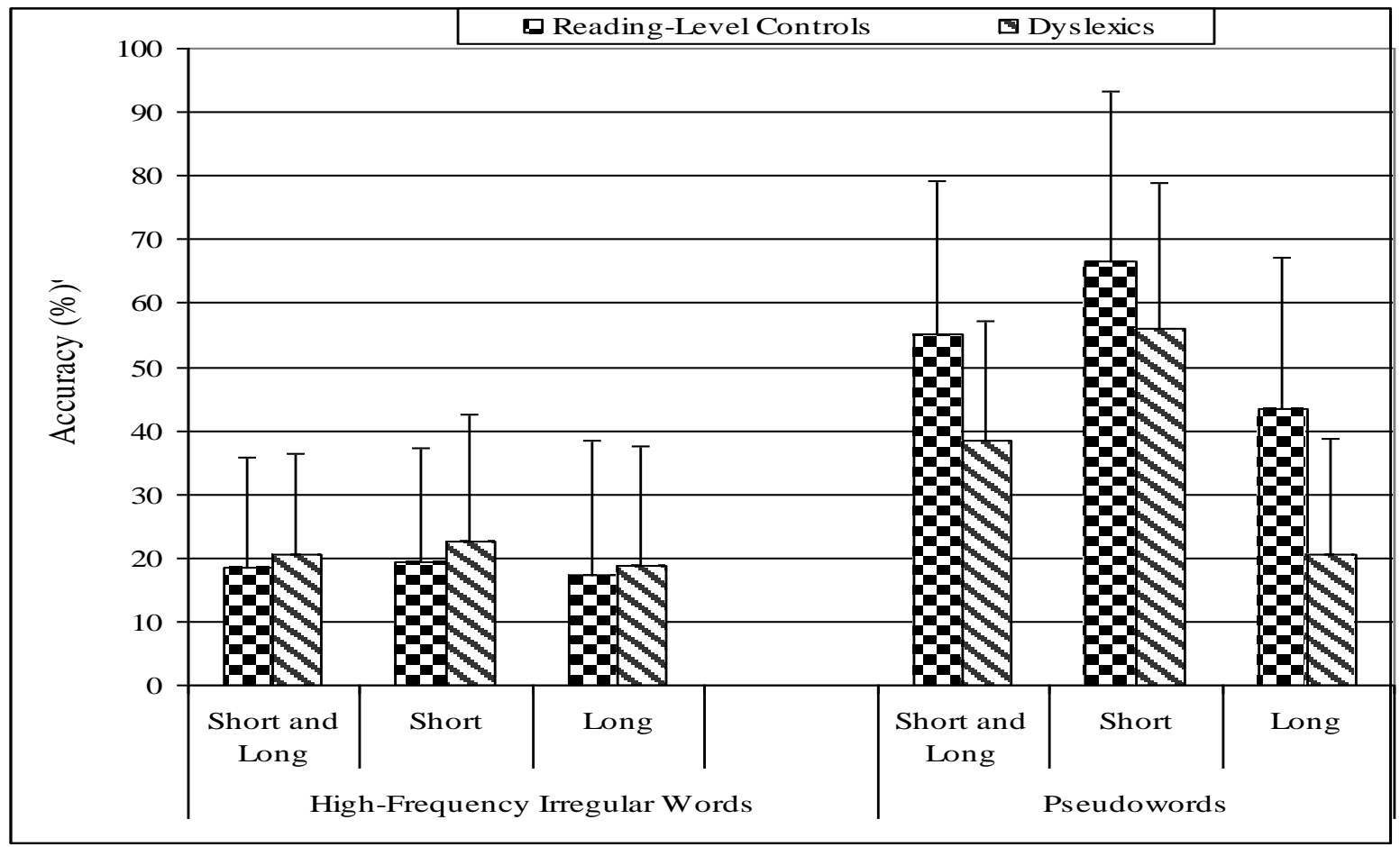




\section{Orthographic choice task}

The mean percentage of correct responses was 54.8\% ( $\mathrm{SD}=30.4)$ for the dyslexics and $64.3 \%$ $(\mathrm{SD}=19.6)$ for the RL controls (the results for only 14 of the 15 children were available). According to a t-test, the difference between the two groups was not significant $(\mathrm{t}(27)=0.99)$. Thus, as for all other tasks in which orthographic skills were assessed (word reading), the dyslexics' performance did not differ from that of younger children of the same reading level.

\section{Phonemic Awareness, Phonological Short-Term Memory, and Rapid Naming}

For the deletion of the first phoneme in $\mathrm{CVC}$ and $\mathrm{CCV}$ pseudowords, the mean percentage of correct responses were respectively $64.4 \%$ and $51.1 \%$ ( $\mathrm{SD}=29.6$ and 26.1 ) for the dyslexics versus $64.4 \%$, and $55.6 \%$ ( $\mathrm{SD}=28.4$ and 25.9 ) for the RL controls. The mean short-term memory span $(\max =6)$ was $4.1(\mathrm{SD}=1.1)$ for the dyslexics versus $3.6(\mathrm{SD}=0.9)$ for the $\mathrm{RL}$ controls. The mean response time for the rapid naming task was $58.5 \mathrm{sec}$. $(\mathrm{SD}=18.2)$ for the dyslexics versus $52.9 \mathrm{sec}$. $(\mathrm{SD}=13.3)$ for the $\mathrm{RL}$ controls (the results for only 12 of the 15 children were available). According to t-tests, the scores of the dyslexics were not significantly lower than those of the RL controls on any of the tasks ( $\mathrm{t}<1$ for each of the 2 phonemic awareness tasks and for the rapid naming; $\underline{t}(28)=-1.5$ for short-term memory), which goes against Hypotheses 5 and 6.

\section{Summary}

In reading-related skills, the scores of the dyslexics did not differ significantly from those of the RL controls. These results failed to support Hypotheses 5 and 6. In reading, the dyslexics' lexical skills never lagged behind those of the RL controls. By contrast, the dyslexics' sublexical skills lagged behind those of the RL controls according to the LEXLENGTH test results, especially for long pseudowords, which is consistent with Hypotheses 1 and 2. In both groups, the lexicality effect was unfavorable to pseudowords in one comparison (regular words vs. pseudowords) and favorable to them in the other (irregular words vs. pseudowords). However, contrary to what was expected, the lexicality effect was not greater for the dyslexics (Hypothesis 3). On the other hand, as expected, the regularity effect was not less pronounced for them (Hypothesis 4). These results indicate that only the dyslexics' phonological reading skills were deficient. However the present study was carried out with a small number of dyslexics, which limits its significance. Consequently, it is crucial to determine the prevalence of phonological deficits in this group of dyslexics.

\section{RESULTS OF THE MULTIPLE-CASE STUDY}

This analysis aimed at ascertaining the proportion of dyslexics whose scores were below the mean of the RL controls (deviant profile) as compared to those whose scores were at the mean of the same control group (delayed profile) or above it (above-average profile). The scores on the different reading and reading-related tasks of each of the 15 dyslexics were compared to those of a RL control group of 86 seven-year-old average readers (see Table 1 and Appendices A, B, and C). To conclude that a dyslexic had a developmentally deviant trajectory, his/her scores had to be more than 1 SD below (for accuracy scores) or above (for processing times) the mean of the RL controls. We also considered the scores that were more than 1.65 SD from the mean of the RL controls because they corresponded to the lowest $5 \%$ of the distribution. To conclude that a dyslexic was suffering only from a developmental delay, his/her scores had to be within the normal range (from -1 SD to +1 SD), and to conclude that he/she had an above-average profile, his/her scores are to be more than $1 \mathrm{SD}$ above (for accuracy) or below (for speed) the mean of the RL controls.

\section{Reading Tasks}

The dyslexics whose scores were more than 1 SD below the RL-control mean for pseudowords only were considered to have deviant phonological skills (or a phonological dyslexia, PD); those whose scores were more than 1 SD below the RL-control mean for irregular words only were considered to have deviant orthographic skills (or a surface dyslexia, SD); those whose scores were more than $1 \mathrm{SD}$ below the RL-control mean on pseudowords and irregular words were considered to have a double 
deficit (or a mixed dyslexia, MD). Phonological skills were assessed by the reading of the LEXORT and LEXLENGTH pseudowords, and orthographic skills by the reading of the LEXORT and LEXLENGTH irregular words as well as by the orthographic choice task. The results for each of the 15 dyslexics, as well as the means and SDs of the RL group, are given in Appendix B. Latencies were not considered in this analysis, the level of accuracy of most of the dyslexics being too low.

The proportion of dyslexics with deviant, delayed, or above-average profiles is presented in Table 2a. For phonological reading skills, the scores of 13 dyslexics (i.e. 87\%) were more than 1 SD below the RL control mean on long LEXLENGTH pseudowords, 11 of whom had a score more than 1.65 SD below the control mean. Deviant phonological skills were less frequent on short LEXLENGTH pseudowords ( 7 dyslexics were more than 1 SD below the control mean, 5 of whom more than 1.65 SD) or LEXORT pseudowords (8 dyslexics with deviant phonological skills, 4 with scores more than $1.65 \mathrm{SD}$ below the control mean). Only 5 dyslexics were found to have deviant orthographic skills for short LEXLENGTH irregular words, 4 for long LEXLENGTH irregular words, and 7 for LEXORT irregular words ( 5 whose scores were more than $1.65 \mathrm{SD}$ ). In the orthographic choice task, 10 dyslexics were found to have deviant orthographic skills, including 4 for whom the orthographic deficit was not observed in irregular-word reading. Finally, very few dyslexics outperformed the RL controls: only 1 for phonological reading skills (D15, and only on 1 out of the 3 pseudoword reading tasks: short LEXLENGTH pseudowords), and 3 for orthographic reading skills (D10, D14, D15), including 1 (D14) whose scores were systematically above the RL control mean on all of these assessments but not on the assessment of his/her phonological reading skills.

Table 2. Reading skills (a) and Reading-Related Skills (b): Proportion and Number of Dyslexics with a Deviant Profile (1 SD or 1.65 below the mean of the RL controls), a Delayed Profile (within the norms of the RL controls), and an Above-Average Profile (1 SD above the mean of the RL controls)

\begin{tabular}{|c|c|c|c|c|c|c|c|}
\hline \multirow{3}{*}{ Table 2a } & \multicolumn{6}{|c|}{ Reading Aloud } & \multirow{3}{*}{\begin{tabular}{|l|}
$\begin{array}{l}\text { Silent } \\
\text { Reading }\end{array}$ \\
$\begin{array}{l}\text { Orthographic } \\
\text { Choice }\end{array}$ \\
\end{tabular}} \\
\hline & \multirow{2}{*}{$\begin{array}{l}\text { LEVORT } \\
\text { Irregular } \\
\text { Words }\end{array}$} & \multirow{2}{*}{$\begin{array}{l}\text { LEXORT } \\
\text { Pseudo- } \\
\text { Words }\end{array}$} & \multicolumn{2}{|c|}{$\begin{array}{l}\text { LEXLENGTH } \\
\text { Irregular Words }\end{array}$} & \multicolumn{2}{|c|}{$\begin{array}{l}\text { LEXLENGTH } \\
\text { Pseudowords }\end{array}$} & \\
\hline & & & Short & & Short & Long & \\
\hline \multirow{2}{*}{$\begin{array}{l}\text { Deviant Profile: }<1 \text { SD } \\
(<1.65 \text { SD })\end{array}$} & $46.7 \%$ & $53.3 \%$ & $33.3 \%$ & $26.7 \%$ & $46.7 \%$ & $86.7 \%$ & $66.7 \%$ \\
\hline & $7(5)$ & $8(4)$ & $5(2)$ & $4(0)$ & & $13(11)$ & $10(8)$ \\
\hline \multirow[t]{2}{*}{ Delayed Profile: Within $\pm 1 \mathrm{SD}$} & $46.7 \%$ & $46.7 \%$ & $53.3 \%$ & $60.0 \%$ & $46.7 \%$ & $13.3 \%$ & $26.7 \%$ \\
\hline & 7 & 7 & 8 & 9 & 7 & 2 & 4 \\
\hline \multirow[t]{2}{*}{\begin{tabular}{|l|} 
Above-Average Profile: > $1 \mathrm{SD}$ \\
\end{tabular}} & $6.7 \%$ & $0 \%$ & $13.3 \%$ & $13.3 \%$ & $6.7 \%$ & $0 \%$ & $6.7 \%$ \\
\hline & & 0 & & 2 & & 0 & 1 \\
\hline
\end{tabular}

\begin{tabular}{|c|c|c|c|c|}
\hline Table $2 b$ & $\begin{array}{l}\text { Phonemic Aw } \\
\text { Accuracy (me }\end{array}$ & $\begin{array}{l}\text { areness } \\
\text { an percentage) }\end{array}$ & $\begin{array}{l}\text { Short-Term Memory } \\
\text { Span }\end{array}$ & \begin{tabular}{|ll} 
Rapid Naming \\
Response Time
\end{tabular} \\
\hline Dyslexic Profile & $\begin{array}{l}1^{\text {st }} \text { Phoneme } \\
\text { Deletion } \\
(\mathrm{CVC}) \\
\end{array}$ & $\begin{array}{l}1^{\text {st }} \text { Phoneme } \\
\text { Deletion } \\
(\mathrm{CCV}) \\
\end{array}$ & $\begin{array}{l}3-\text { to } 6-\text { Syllable } \\
\text { Pseudoword } \\
\text { Repetition }\end{array}$ & \begin{tabular}{|l|} 
Color \\
Patches
\end{tabular} \\
\hline $\begin{array}{l}\text { Deviant Profile: }<1 \mathrm{SD} \\
(<1.65 \mathrm{SD})\end{array}$ & $\begin{array}{l}40.0 \% \\
6(5)\end{array}$ & $\begin{array}{l}20.0 \% \\
3(1)\end{array}$ & $\begin{array}{l}6.7 \% \\
1(1)\end{array}$ & $\begin{array}{l}13.3 \% \\
2(1)\end{array}$ \\
\hline Delayed Profile: Within $\pm 1 \mathrm{SD}$ & $\begin{array}{l}53.3 \% \\
8 \\
\end{array}$ & $\begin{array}{l}73.3 \% \\
11 \\
\end{array}$ & $\begin{array}{l}53.3 \% \\
8 \\
\end{array}$ & $\begin{array}{l}73.3 \% \\
11 \\
\end{array}$ \\
\hline Above-Average Profile: > 1 SD & $\begin{array}{l}6.7 \% \\
1\end{array}$ & $\begin{array}{l}6.7 \% \\
1\end{array}$ & $\begin{array}{l}40.0 \% \\
6\end{array}$ & $\begin{array}{l}13.3 \% \\
2\end{array}$ \\
\hline
\end{tabular}


The dyslexics with deviant or delayed phonological and/or orthographic skills are presented in Figure 3. Based on pseudoword and irregular-word reading, there were 5 dyslexics with a deviant phonological profile (PD), none with a deviant surface profile (SD), 8 dyslexics with deviant phonological and orthographic skills (mixed profile, MD), and 2 with a delayed profile (scores within the normal range, DD). When accuracy scores from the orthographic choice task were considered, the number of mixed profiles increased (10 dyslexics), that of deviant phonological profiles decreased (3 dyslexics), and 2 deviant surface profiles emerged.

Figure 3. Reading: Dyslexics with Deviant Phonological Reading Skills (accuracy on long pseudowords) and/or Orthographic Reading Skills (accuracy on irregular words and on the orthographic choice task)

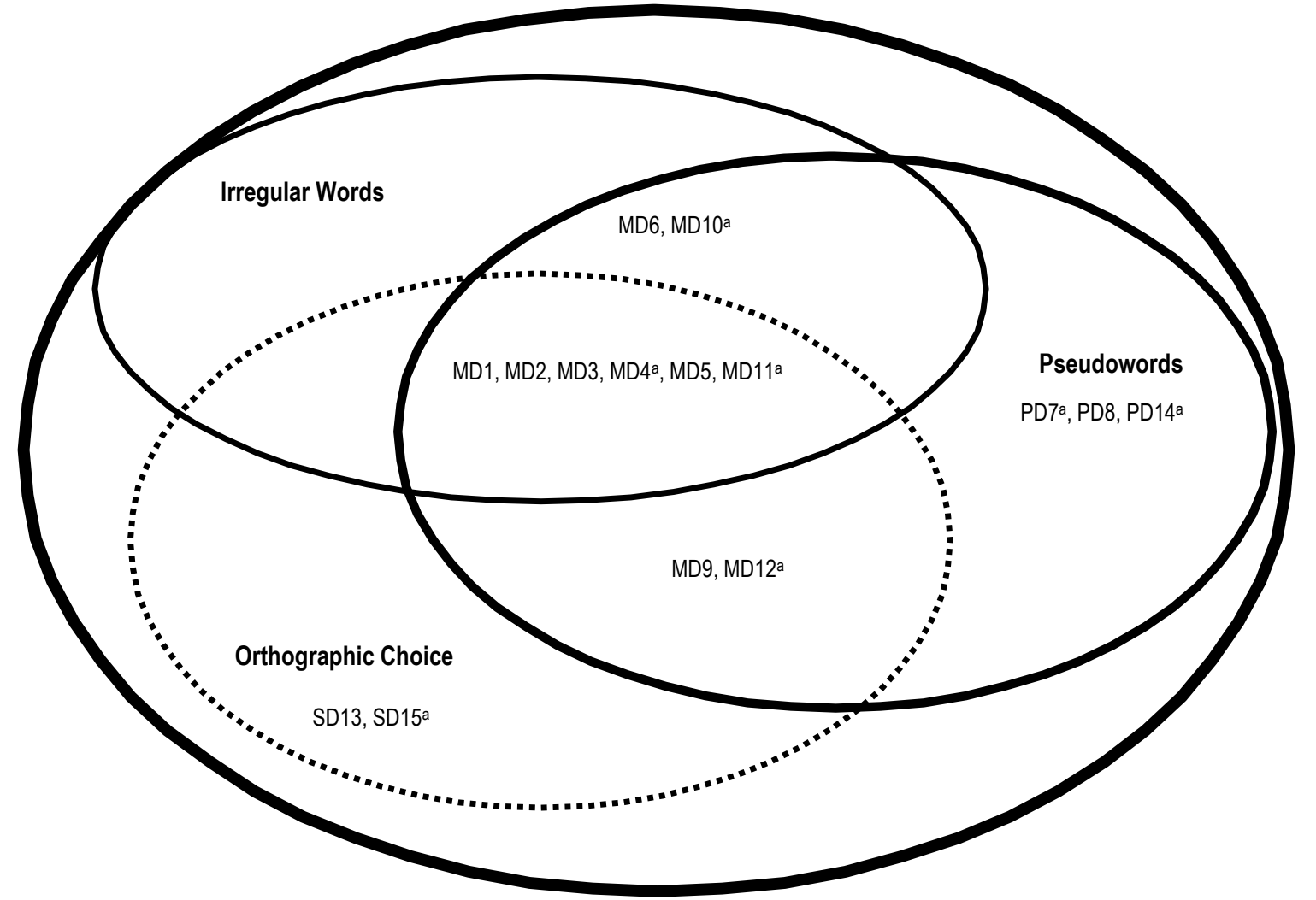

Note. In the large outer oval, we find the 15 dyslexics, and in each of the three inner ovals we find those whose scores were deviant (1 or 1.65 SDs below the mean of the RL controls)

- a. Dyslexics who were in the special school the year before

- PD (phonological dyslexia): Dyslexics with only deviant phonological reading skills based on pseudoword accuracy scores

- SD (surface dyslexia): Dyslexics with only deviant orthographic skills based on irregular word and/or orthographic choice accuracy scores

- MD (mixed profile): Dyslexics with deviant phonological and orthographic reading skills

\section{Reading-Related Tasks}

The performance of the dyslexics was considered to be deviant, delayed, or above-average on the basis of the same criteria as before. The proportion of the different profiles is presented in Table $2 b$ (see also the results for each of the 15 dyslexics, and the means and SDs of the RL group in Appendix C). Only 8 dyslexics were found to have deviant skills in reading-related tasks. In addition, strong differences between the tasks were observed. In the two phoneme-deletion tasks, 7 dyslexics exhibited deviant scores (more than 1.65 SD below the control mean for 6 of them) whereas only 1 did in the short-term memory task and only 2 in the rapid naming task. Only 1 dyslexic outperformed the RL 
controls on phoneme-deletion task, 2 on rapid naming task, but 6 on phonological short-term memory.

In Figure 4, all of the dyslexics are inside the largest oval, those with deviant phonological reading skills are inside the large dotted-line oval, and those with deviant scores in phonological awareness, phonological short-term memory, and rapid naming are in the four small ovals. All 8 dyslexics with deviant phonological skills in reading-related tasks also had deviant phonological skills in reading. One of these dyslexics suffered only from a naming deficit (PD7). Note that the scores of this child were within the control norms on all assessments of his/her orthographic reading skills, whereas they were more than 1 SD below the control mean on all the assessments of his/her phonological reading skills (and more than 1.65 SD on 2 out of the 3 pseudoword reading tasks). Finally, among the 7 dyslexics with non-deviant phonological skills on the reading-related tasks, 5 had deviant phonological reading skills but neither of the 2 dyslexics who seemed to have unimpaired phonological reading skills (SD13, SD15) had a deficit on the reading-related tasks.

Figure 4. Dyslexics with Deviant Phonological Skills on Reading (pseudoword accuracy, large dottedline oval) and Reading-Related Tasks (phoneme deletion, rapid naming, phonological short-term memory: STM)

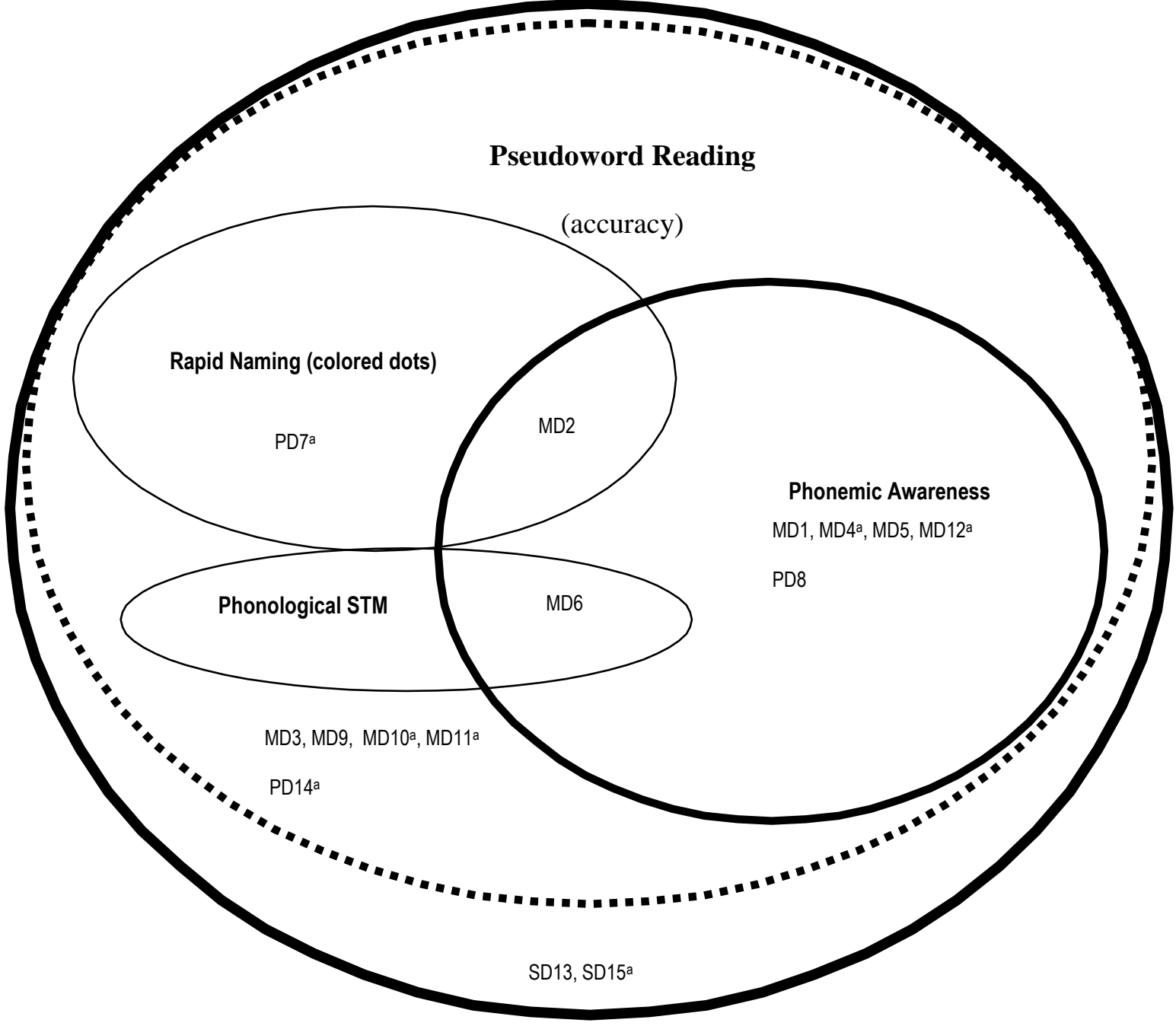

- a. Dyslexics who were in the special school the year before

- PD (phonological dyslexia): Dyslexics with only deviant phonological reading skills based on pseudoword accuracy scores

- SD (surface dyslexia): Dyslexics with only deviant orthographic skills based on irregular word and/or orthographic choice accuracy scores

- MD (mixed profile): Dyslexics with deviant phonological and orthographic reading skills 
Complementary Examinations of the Dyslexics with No Deviant Phonological Reading Skills

Two dyslexics appeared to have unimpaired phonological reading skills (SD13 and SD15). However, the scores of these children lagged more than 1 SD below the mean of the RL controls on one of the orthographic-skill assessment (accuracy on the orthographic choice task). These two dyslexics were thus potential candidates for a deviant surface profile. In addition, the score of another dyslexic (PD14) was very near the threshold of 1 SD for long pseudoword reading (40.9, PD14 score $=40)$, a phonological deficit was never observed in the other two pseudoword reading tasks for this child, whose orthographic skills were systematically above the RL control mean. To be sure that the phonological skills of these 3 dyslexics are not deviant, it is necessary to examine the time taken to process the pseudowords they read accurately, so we looked at their pseudoword latencies. In order to determine whether their deficit was specific to phonological processing, we also considered irregularword latency and response time for correct responses in the orthographic choice task. This was possible because these dyslexics produced about 50\% correct responses, except in the reading of short LEXLENGTH irregular words for 2 of them (SD13 and SD15) and long LEXLENGTH irregular words for 1 of them (SD13). Thus we only considered the data for the irregular LEVORT words, the LEXORT pseudowords, and the orthographic choice task. The normative data came from the RL controls able to correctly read more than $50 \%$ of the items: out of the $86 \mathrm{RL}$ controls, 53 children for the LEVORT irregular words and LEXORT pseudowords, and 83 for the orthographic choice task. According to the Alouette reading test, the reading ages of dyslexics SD13, PD14 and SD15 (83, 83, and 91 months, respectively) were within the norms of the 83 and 53 RL controls (respectively, 85 months, $\mathrm{SD}=5$ and 87 months, $\mathrm{SD}=4$ ). Latencies on pseudoword and irregular-word, and response times on the orthographic choice task, are presented in Table 3.

Only 1 of the 6 usable orthographic scores was at least 1 SD above the mean of the RL controls (SD13 for irregular words). This was the case for 3 of the usable phonological scores. So, for the 3 dyslexics for whom a phonologically deviant profile was not found according to their accuracy scores, this profile was revealed by their latencies.

Table 3. Latency on Reading-Aloud Tasks (in ms) and Response Time in the Silent-Reading Task (in ms) for RL Controls and for the Three Dyslexics with Scores within the Norms Based on Accuracy (deviant profile: grey highlighting)

\begin{tabular}{|l|l|l|c|}
\hline & $\begin{array}{l}\text { LEVORT } \\
\text { Irregular word }\end{array}$ & $\begin{array}{l}\text { LEXORT } \\
\text { Pseudoword }\end{array}$ & Orthographic Choice \\
\hline Dyslexics & $* * 4171(3335)$ & $* * 3862(1315)$ & $6376(0901)$ \\
D13 Mean (SD) & $1584(0808)$ & $* * 3743(1045)$ & $10330(3543)$ \\
D14 Mean (SD) & $* 2760(0804)$ & $5820(1122)$ \\
D15 Mean (SD) & $2324(1089)$ & & \\
& & & \\
\hline RL Controls & ${ }^{a} 1672(730)$ & 2986 & $8053(3012)$ \\
Mean (SD) & 2877 & 2533 & 13023 \\
+1.65 SD & 2402 & 1136 & 5041 \\
+1 SD & 942 & & \\
-1 SD & &
\end{tabular}

** and * latency of 1.65 or $1 \mathrm{SD}$ above the RL control mean, respectively

a: Mean of the $53 \mathrm{RL}$ controls (out of 86 ) with a $50 \%$ or more correct response rate

\section{GENERAL DISCUSSION}

$\underline{\text { Reading Skills }}$

In the group study, the accuracy scores of the dyslexics lagged behind those of the RL controls only when the phonological procedure was used, and only when the task included difficult items such as 
long pseudowords. These results are consistent with Hypotheses 1 and 2. They indicate that, compared to RL controls, dyslexics suffer from a phonological deficit. The fact that this deficit was observed only when the dyslexics were required to read the most difficult pseudowords in the present French study, which seemed not to be the case in English (Rack et al., 1992; Van Ijzendoorn \& Bus, 1994), may be due to the greater transparency of GPC in French, compared to English. Therefore, French-speaking dyslexics may manage to use the sublexical reading route with less difficulty than English-speaking dyslexics, especially when they have to read simple pseudowords.

The regularity effect was strong for both groups (37\%), and was not smaller for the dyslexics. These results, which support Hypothesis 4, could be explained by the fact that both word frequency and regularity help children learn to read, with a combination of the two helping the most. Accordingly, items that can be processed by relying on both the lexical and sublexical reading routes, namely high frequency regular words, may be easier to read, even for dyslexic children, because there are two main keys to accessing them.

The presence of a selective deficit in pseudoword reading in dyslexics compared to RL controls is consistent with the results of previous studies conducted with English-speaking dyslexics (for reviews, see Rack et al., 1992; Van Ijzendoorn \& Bus, 1994), as was the presence of equivalent regularity effects in dyslexics compared to RL controls (for a review, see Metsala et al., 1998).

Conversely, Hypothesis 3 was not validated because the lexicality effect was not greater for the dyslexics than for the RL controls. In fact, two unexpected results on the lexicality effect were observed: this effect was not significantly greater for the dyslexics than for the RL controls in the comparison between regular words and pseudowords; and it was even greater for the RL controls in the comparison between irregular words and pseudowords. In addition, the lexicality effect was to the disadvantage of pseudowords in the comparison with regular words and to the advantage of pseudowords in the comparison with irregular words.

The superiority of regular words over pseudowords can be explained by the fact that the regular words used in this study were frequent, and thus benefited from both a word-frequency advantage and a grapheme-phoneme regularity advantage, whereas pseudowords benefited from only the latter effect. This result replicates that observed with 7-year-old children in previous studies involving average readers (Sprenger-Charolles et al., 2003 and 2005), where a superiority of regular words over pseudowords was observed, as in the present study. For those children as well, the lowest scores were observed for irregular words compared to pseudowords, again as in the present study. The poorer performance on high-frequency irregular words compared to pseudowords may be due to the fact that, at that early stage of reading acquisition, average readers rely more strongly on phonological skills than on lexical ones.

This interpretation helps us understand the first unexpected result, i.e. why the lexicality effect in the comparison between irregular words and pseudowords was so great for the RL controls $(-36.7 \%$ difference between irregular words and pseudowords, $18.3 \%$ vs. $55 \%$, respectively) and even greater than for the dyslexics (-17.7\% difference between irregular words and pseudowords, $20.7 \%$ vs. $38.4 \%$, respectively). The fact that this 'inverse' effect of lexicality was weaker for the dyslexics can be explained by both their seriously impaired phonological reading skills (leading to very low scores, especially on long pseudowords) and their relatively preserved orthographic skills (their scores on irregular words being equivalent to those of the younger RL controls).

The second unexpected result was that the lexicality effect observed in the comparison between regular words and pseudowords, which was advantageous on words for both groups, was not greater for the dyslexics. A similar result was found on the basis of accuracy scores in a study involving older English and German dyslexics and RL controls (Ziegler, Perry, Ma-Wyatt, Ladner, \& Schulte-Körne, 2003). As in the present study, the interaction between lexicality and group was not significant, nor was the interaction between group, lexicality, and language, thus indicating that the deficit in pseudoword reading was not greater for the dyslexics, whatever their language. However, the interaction between lexicality and group was found in the latency data. These results suggest that, when the pseudowords are not too difficult, dyslexics are able to correctly match each grapheme to the appropriate phoneme. Their phonological deficit may only show up as slow pseudoword reading, as was the case in the previous French study with older dyslexics (Sprenger-Charolles et al., 2000).

It may be added that the length effect was more marked for pseudowords than for irregular words. 
This result suggests that these two types of items are not processed in entirely the same way. Indeed, the more people rely on serial phonological processing, the greater the length effect is. The results we obtained, which replicate those observed with adults (e.g. Weekes, 1997) ${ }^{3}$, are thus consistent with the idea that words benefit from some direct parallel orthographic processing whereas pseudowords need to be decoded in a serial mode.

In addition, the results of the multiple-case study indicated that the prevalence of the phonological deficit was extremely high (the accuracy scores of 13 out of 15 dyslexics were more than 1 SD below the mean of the RL controls for long pseudowords). Less than half of these dyslexics were found to have deviant orthographic skills based on accuracy for LEVORT irregular words and less than a third based on accuracy on the other two irregular-word reading tasks. However, in the orthographic choice task, a deficit was found for a significant number of dyslexics (10 dyslexics, 66.7\%), thus suggesting that their orthographic skills are not firmly established. In regard to the method generally used to classify dyslexics (irregular vs. pseudoword accuracy), 8 dyslexics presented a mixed profile, 5 a phonological profile, and 2 a delayed profile. We were able to examine the latency data of the 3 dyslexics who, according to their accuracy scores, seemed to have unimpaired phonological reading skills ( 2 dyslexics) or a mild phonological deficit (1 dyslexic). Based on their latencies, only the phonological reading skills of these 3 dyslexics lagged systematically behind those of the RL controls. The results of the multiple-case study thus suggest that the phonological reading-skill deficit of dyslexics is clearly prevalent.

\section{$\underline{\text { Reading-Related Skills }}$}

In the group study, dyslexics were found to perform no differently from RL controls, no matter what was at stake (phonemic awareness, phonological short-term memory, or rapid naming), therefore Hypotheses 5 and 6 were not validated. The results replicated those found in some earlier studies on rapid naming, where significant differences were not always observed between dyslexics and RL controls (e.g. Pennington et al., 2001) or even CA controls (e.g. Ramus, Pidgeon, \& Frith, 2003). They also replicated the results of some previous studies on phonological short-term memory, where dyslexics were not found to lag behind RL controls (e.g. Pennington et al., 2001) or even CA controls (e.g. Bowers, 1995; Wimmer, 1993). In addition, the results of the multiple-case study indicated that the prevalence of these deficits is very low: 1 case for phonological short-term memory and 2 cases for rapid naming. Note that only one dyslexic was found to have a selective impairment in rapid naming, without any deficits in phonemic awareness. However, since the lexical reading skills of this dyslexic were fairly well-preserved, but not his/her sublexical reading skills (his/her scores were in the normal range for word reading but were below the RL controls' for pseudoword reading), this case does not support the hypothesis that there are two different sources of reading disabilities, one due to phonemic awareness deficit that leads to an impaired phonological reading route, the other due to inaccurate access to the lexicon (usually assessed by processing speed in the rapid automatic naming of highly frequent items) that leads to an impaired lexical reading route (see Wolf et al., 2002).

More surprising in the present study was the lack of a significant difference between the dyslexics and the RL controls on two phoneme-deletion tasks. In most earlier studies, a phonemic-awareness deficit was observed in dyslexics compared to RL controls in English (e.g. Bowers, 1995; Bruck, 1992; Chiappe et al., 2002; Joanisse, Manis, Keating, \& Seidenberg, 2000; Pennington et al., 2001), as well as in dyslexics faced with a more transparent orthography (e.g. Spanish: Jimenez-Gonzalez, \& Ramirez-Santana, 2002; Czech: Caravolas et al., 2005; German: Landerl et al., 1997; but see Landerl \& Wimmer, 2000). However, in the present study, 7 of the 15 dyslexics were found to have lower scores than RL controls in phonemic awareness, including two dyslexics with an additional deficit either in phonological short-term memory or in rapid naming. The proportion of dyslexics exhibiting a deficit in tasks requiring phonemic awareness, although low, was thus higher than that of dyslexics exhibiting a deficit in phonological short-term memory or in rapid naming. The fact that deviant skills were not prevalent in phonemic awareness can be explained by the intensive phonological awareness training some of the dyslexics enrolled in the present study had undergone ${ }^{2}$. This interpretation is supported by the fact that deficits in phonemic awareness were found for only 2 of the 7 children who had been attending the institute for 12 months (including one child for which the deficit was mild: it was observed only in one task and his/her scores were only 1 SD below the control mean), while they 
were found for 5 children of the 8 newly arriving dyslexics. The intensive training outside the domain of reading does not seem to have had a strong effect on their phonological reading abilities however, since in the most difficult phonological reading task - the one involving long pseudowords - all of these dyslexics exhibited a deviant profile. These results suggest that it is difficult to compensate for phonological reading deficits (Vellutino, Scanlon, Sipay, Small, Pratt, Chen, \& Denckla, 1996) and, that training in phonological tasks not based on reading might improve dyslexic's ability to perform other similar phonological tasks but does not systematically improve reading (Hurford, Johnston, Nepote, Hampton, Moore, Neal, Mueller, McGeorge, Huff, Awad, Tatro, Juliano, \& Huffman, 1994).

\section{Concluding Remarks}

The results of the present study are consistent with those of previous research that have noted that the impairment of dyslexics' phonological reading route emerges in group studies even in comparison with RL controls and is prevalent. The fact that this impairment has mostly been observed on pseudoword reading accuracy in a deep orthography, and mostly on pseudoword reading speed in languages with a shallower orthography, suggests that the manifestations of developmental dyslexia depend both on universal principles and language-specific features. However, in the present study conducted in French almost all dyslexics were found to have deviant phonological reading skills according to their pseudoword accuracy scores, at least for difficult pseudowords. These results replicate and reinforce those found in a previous French study involving older and less severely impaired dyslexics (Sprenger-Charolles et al., 2000) in which the pseudoword reading deficit was found to be prevalent mainly according to processing speed, not to accuracy scores.

The most striking findings came out from the outcomes of the comparison between pseudoword reading and either regular word reading (the comparison mainly used in languages with a shallow orthography) or irregular word reading (the comparison mainly used with English-speaking dyslexics). Indeed, the difference between regular words and pseudowords was to the detriment of pseudowords (and was not greater for the dyslexics) whereas the difference between irregular words and pseudowords was to the benefit of pseudowords (and was more significant for the RL controls). These findings will make it possible to understand some inconsistencies between studies carried out either in English or in a language with a shallower orthography (Spanish, or French, for instance).

In the light of the findings of group studies demonstrating the high reliability of the deficit of the dyslexic sublexical reading route and of multiple-case studies indicating the high prevalence of this deficit, the conclusion that poor phonological reading skills are the basis of reading impairment in dyslexia seems unavoidable (Siegel, 1993; Stanovich, \& Siegel, 1994). These results are not congruent with Castles and Coltheart's idea that 'a clear double dissociation exists between surface and phonological reading patterns' (1993, p. 174).

\section{$\underline{\text { NOTES }}$}

1. We did not include four studies: three because there were no RL comparisons (Castles et al., 1999; Milne, Nicholson, \& Corballis, 2003; Zabell \& Everatt, 2002); one because the classification was not based on pseudoword reading (McDougall, Borowsky, MacKinnon, \& Hymel, 2004).

2. In the center in which the dyslexics were schooled, the children were in classes with a small number of classmates (7) for 25 hours a week for one or two years. They benefited from individual training by a speech therapist (45 minutes, 4 days a week). This training is mainly devoted to developing their phonemic awareness, their decoding skills, and their orthographical skills.

3. In another study (Ziegler et al., 2003), there was no interaction between length and lexicality, so the word and pseudoword data were combined. This made a comparison with our results impossible. 


\section{APPENDICES}

Characteristics of the Dyslexics (group and multiple-case studies) and the RL Controls (group study), ranked from 1 to 15 Based on Reading Age

\begin{tabular}{|c|c|c|c|c|c|c|c|c|c|}
\hline & Gender & $\begin{array}{l}\text { Chronol. } \\
\text { Age } \\
\text { (months) }\end{array}$ & \begin{tabular}{|l|} 
Non-verbal \\
IQ (RAVEN \\
percentile)
\end{tabular} & \begin{tabular}{|l|} 
Reading \\
Age \\
Alouette \\
(months)
\end{tabular} & & Gender & $\begin{array}{l}\text { Chronol. } \\
\text { Age } \\
\text { (months) }\end{array}$ & $\begin{array}{l}\text { Non-verbal } \\
\text { IQ (RAVEN } \\
\text { Percentile) }\end{array}$ & $\begin{array}{l}\text { Reading } \\
\text { Age } \\
\text { Alouette } \\
\text { (months) }\end{array}$ \\
\hline \multicolumn{5}{|c|}{ Dyslexics (group and multiple-case studies) } & \multicolumn{5}{|c|}{ RL Controls (group study) } \\
\hline D1 & $\mathrm{M}$ & 94 & 25 & 78 & N1 & $\mathrm{M}$ & 80 & 25 & 78 \\
\hline $\mathrm{D} 2$ & M & 100 & 50 & 78 & $\mathrm{~N} 2$ & M & 84 & 50 & 78 \\
\hline D3 & $\mathrm{F}$ & 110 & 75 & 78 & N3 & $\mathrm{F}$ & 83 & 75 & 78 \\
\hline $\mathrm{D} 4^{\mathrm{a}}$ & M & 117 & 95 & 79 & N4 & M & 85 & 95 & 79 \\
\hline D5 & $\mathrm{M}$ & 109 & 50 & 79 & N5 & M & 89 & 75 & 79 \\
\hline D6 & $\mathrm{M}$ & 118 & 50 & 79 & N6 & M & 87 & 50 & 79 \\
\hline $\mathrm{D} 7^{\mathrm{a}}$ & M & 109 & 95 & 79 & N7 & $\mathrm{F}$ & 82 & 95 & 79 \\
\hline D8 & $\mathrm{F}$ & 117 & 25 & 79 & N8 & $\mathrm{F}$ & 88 & 25 & 79 \\
\hline D9 & $\mathrm{M}$ & 118 & 25 & 80 & N9 & $\mathrm{M}$ & 89 & 25 & 80 \\
\hline $\mathrm{D} 10^{\mathrm{a}}$ & $\mathrm{F}$ & 109 & 90 & 80 & N10 & M & 87 & 50 & 80 \\
\hline $\mathrm{D} 11^{\mathrm{a}}$ & $\mathrm{F}$ & 105 & 90 & 80 & N11 & $\mathrm{F}$ & 77 & 75 & 80 \\
\hline $\mathrm{D} 12^{\mathrm{a}}$ & $\mathrm{F}$ & 113 & 25 & 80 & $\mathrm{~N} 12$ & $\mathrm{~F}$ & 86 & 50 & 80 \\
\hline D13 & $\mathrm{M}$ & 105 & 90 & 83 & N13 & M & 79 & 90 & 83 \\
\hline $\mathrm{D} 14^{\mathrm{a}}$ & $\mathrm{F}$ & 127 & 50 & 83 & N14 & $\mathrm{F}$ & 87 & 25 & 83 \\
\hline $\mathrm{D} 15^{\mathrm{a}}$ & $\mathrm{M}$ & 109 & 25 & 91 & N15 & $\mathrm{F}$ & 84 & 25 & 91 \\
\hline $\begin{array}{l}\text { Mean } \\
\text { SD }\end{array}$ & $\begin{array}{l}9 \mathrm{M} / 6 \\
\mathrm{~F}\end{array}$ & $\begin{array}{r}111 \\
(8)\end{array}$ & $\begin{array}{r}57.3 \\
(29.0)\end{array}$ & $\begin{array}{l}80 \\
(3)\end{array}$ & & $8 \mathrm{M} / 7 \mathrm{~F}$ & $\begin{array}{l}85 \\
(4)\end{array}$ & $\begin{array}{r}55.3 \\
(27.0)\end{array}$ & $\begin{array}{l}80 \\
\text { (3) }\end{array}$ \\
\hline
\end{tabular}

Gender (M: male, F: female); a: Dyslexics who were in the special school the year before 
B. Reading Tasks: Mean Percentage of Correct Responses for Each Dyslexic and for the RL Controls ( $\mathrm{N}=86$, multiple-case studies)

\begin{tabular}{|c|c|c|c|c|c|c|c|}
\hline & \multicolumn{6}{|l|}{ Reading Aloud } & \multirow{2}{*}{$\begin{array}{l}\text { Silent Reading } \\
\text { Orthographic } \\
\text { Choice }\end{array}$} \\
\hline & $\begin{array}{l}\text { LEVORT } \\
\text { Irregular Words }\end{array}$ & \begin{tabular}{|l} 
LEXORT \\
Pseudowords
\end{tabular} & \multicolumn{2}{|c|}{\begin{tabular}{|l} 
LEXLENGTH \\
Irregular Words
\end{tabular}} & \multicolumn{2}{|c|}{$\begin{array}{l}\text { LEXLENGTH } \\
\text { Pseudowords }\end{array}$} & \\
\hline \multicolumn{8}{|c|}{ Dyslexics (group and multiple-case studies) } \\
\hline D1 & $* * 00.0$ & $* * 30.6$ & $* * 00$ & $* 00$ & 70 & $* * 20$ & $* * 33.3$ \\
\hline D2 & $* * 00.0$ & $* 38.9$ & $* * 00$ & $* 00$ & $* * 30$ & $* * 20$ & $* * 00.0$ \\
\hline D3 & $* * 00.0$ & $* * 11.1$ & 20 & $* 00$ & $* * 30$ & $* * 00$ & $* * 44.4$ \\
\hline $\mathrm{D} 4^{\mathrm{a}}$ & $* 16.7$ & $* * 16.0$ & $* 10$ & 10 & $* 50$ & $* * 00$ & $* * 33.3$ \\
\hline D5 & $* * 00.0$ & 58.3 & 20 & 10 & 80 & $* * 20$ & $* * 44.4$ \\
\hline D6 & $* * 08.3$ & 52.8 & $* 10$ & 40 & 80 & $* * 20$ & 77.8 \\
\hline $\mathrm{D} 7^{\mathrm{a}}$ & 75.0 & *36.1 & 20 & 20 & $* * 30$ & $* * 10$ & 88.9 \\
\hline D8 & 33.3 & *38.9 & 20 & 10 & $* * 20$ & $* * 10$ & 88.9 \\
\hline D9 & 33.3 & 47.2 & 40 & 30 & 60 & $* 30$ & $* * 44.4$ \\
\hline $\mathrm{D} 10^{\mathrm{a}}$ & 33.3 & $* 38.9$ & ++70 & $* 00$ & $* 50$ & $* * 00$ & 88.9 \\
\hline $\mathrm{D} 11^{\mathrm{a}}$ & $* 25.0$ & 61.1 & $* 10$ & 10 & 60 & $* * 20$ & $* 66.7$ \\
\hline $\mathrm{D} 12^{\mathrm{a}}$ & 33.3 & $* * 22.2$ & 20 & 20 & $* * 40$ & $* * 10$ & $* * 00.0$ \\
\hline D13 & 50.0 & 75.0 & 20 & 20 & 70 & 50 & $* * 44.4$ \\
\hline $\mathrm{D} 14^{\mathrm{a}}$ & ++91.7 & 77.8 & ++60 & ++60 & 70 & $* 40$ & ++100.0 \\
\hline $\mathrm{D} 15^{\mathrm{a}}$ & 66.7 & 52.8 & 20 & ++50 & ++100 & 60 & $* 66.7$ \\
\hline \multicolumn{8}{|c|}{ RL Controls ( $N=86$, multiple-case study) } \\
\hline Mean & 52.0 & 63.9 & 28.6 & 27.0 & 74.4 & 62.6 & 82.9 \\
\hline SD & 24.5 & 16.9 & 17.0 & 22.0 & 19.5 & 21.7 & 15.6 \\
\hline$-1.65 \mathrm{SD}$ & 11.7 & 36.1 & 0.6 & 0.0 & 42.2 & 26.8 & 57.2 \\
\hline$-1 \mathrm{SD}$ & 27.6 & 47.0 & 11.7 & 5.0 & 54.9 & 40.9 & 67.3 \\
\hline$+1 \mathrm{SD}$ & 76.5 & 80.7 & 45.6 & 48.9 & 93.9 & 84.2 & 98.4 \\
\hline
\end{tabular}

- a. Dyslexics who were in the special school the year before

- Deviant profile (grey highlighting): Scores 1.65 SD (**) or $1 \mathrm{SD}(*)$ below the mean of RL controls

- Above-average profile (more than 1 SD above the mean of RL controls): ++

- Delayed profile (in the normal range) 
C. Phonemic Awareness (accuracy scores: percentage), Phonological Short-Term Memory (span) and Rapid Naming (response time) for Each Dyslexic and for the RL Controls ( $\mathrm{N}=86)$

\begin{tabular}{|c|c|c|c|c|}
\hline & \multicolumn{2}{|c|}{$\begin{array}{l}\text { Phonemic awareness } \\
\text { (mean percentage of } \\
\text { correct responses) }\end{array}$} & \multirow[t]{2}{*}{$\begin{array}{l}\text { Phonological Short- } \\
\text { Term Memory } \\
\text { (span: } \max =6)\end{array}$} & \multirow[t]{2}{*}{$\begin{array}{l}\text { Rapid Naming } \\
\text { Mean Response Times } \\
\text { (colored dots) }\end{array}$} \\
\hline & $\begin{array}{l}\mathrm{CVC} \\
\end{array}$ & $\mathrm{CCV}$ & & \\
\hline D1 & $* * 08.3$ & $* 25.0$ & 3 & 51 \\
\hline D2 & 66.7 & $* * 00.0$ & 4 & $* 89$ \\
\hline D3 & 75.0 & 41.7 & 3 & 75 \\
\hline $\mathrm{D} 4^{\mathrm{a}}$ & *58.3 & 83.3 & ++5 & 59 \\
\hline D5 & $* * 33.3$ & 58.3 & 4 & 57 \\
\hline D6 & $* * 41.7$ & 75.0 & $* * 2$ & 48 \\
\hline $\mathrm{D} 7^{\mathrm{a}}$ & 83.3 & ++91.7 & ++5 & $* * 101$ \\
\hline D8 & $* * 41.7$ & 58.3 & 4 & 57 \\
\hline D9 & 91.7 & 50.0 & ++6 & 51 \\
\hline $\mathrm{D} 10^{\mathrm{a}}$ & 91.7 & 75.0 & 3 & 47 \\
\hline $\mathrm{D} 11^{\mathrm{a}}$ & ++100.0 & 33.3 & ++5 & 61 \\
\hline $\mathrm{D} 12^{\mathrm{a}}$ & $* * 16.7$ & $* 16.7$ & 4 & 46 \\
\hline D13 & 91.7 & 41.7 & ++5 & ++36 \\
\hline D14 ${ }^{\mathrm{a}}$ & 91.7 & 75.0 & ++5 & 65 \\
\hline D15 ${ }^{\mathrm{a}}$ & 75.0 & 41.7 & 4 & ++35 \\
\hline \multicolumn{5}{|c|}{ RL Controls ( $\mathrm{N}=86$, multiple-case study) } \\
\hline Mean & 82.8 & 58.4 & 3.9 & $\overline{58.8}$ \\
\hline SD & 20.6 & 27.2 & 0.9 & 21.2 \\
\hline$-1.65 \mathrm{SD}$ & 48.8 & 13.6 & 2.4 & 93.7 \\
\hline$-1 \mathrm{SD}$ & 62.2 & 31.3 & 3.0 & 80.0 \\
\hline$+1 \mathrm{SD}$ & 100.0 & 85.6 & 4.7 & 37.7 \\
\hline
\end{tabular}

- a. Dyslexics who were in the special school the year before

- Deviant profile (grey highlighting): Scores $1.65 \mathrm{SD}\left({ }^{*}\right)$ or $1 \mathrm{SD}(*)$ below the mean of RL controls (or above for processing time)

- Above-average profile (more than 1 SD above the mean of RL controls for accuracy scores or below for processing time): ++

- Delayed profile (in the normal range) 


\section{REFERENCES}

Backman, J., Bruck, M., Hebert, M., \& Seidenberg, M.S. (1984). Acquisition and use of spelling sound correspondences in reading. Journal of Experimental Child Psychology, 38, 114-133.

Bowers, P.G. (1995). Tracing symbol naming speed's unique contributions to reading disabilities over time. Reading and Writing: An Interdisciplinary Journal, 7, 189-216.

Bruck, M. (1992). Persistence of dyslexics' phonological awareness deficits. Developmental Psychology, 28, 874-886.

Bryant, P., \& Impey, L. (1986). The similarities between normal readers and developmental and acquired dyslexics. Cognition, 24, 121-137.

Caravolas, M., Volin, J., \& Hulme, C. (2005). Phoneme awareness is a key component of alphabetic literacy skills in consistent and inconsistent orthographies: Evidence from Czech and English children. Journal of Experimental Child Psychology, 92, 107-139.

Casalis, S. (1995). Lecture et dyslexies de l'enfant. Paris: Septentrion.

Castles, A., \& Coltheart, M. (1993). Varieties of developmental dyslexia. Cognition, 47, 149-180.

Castles, A., Datta, H., Gayan, J., \& Olson, R.K. (1999). Varieties of reading disorder: Genetic and environmental influences. Journal of Experimental Child Psychology, 72, 73-94.

Chiappe, P., Stringer, N., Siegel, L.S., \& Stanovich, K. (2002). Why the timing deficit hypothesis does not explain reading disability in adults. Reading and Writing: An Interdisciplinary Journal, $15,73-107$.

Coltheart, M., Curtis, B., Atkins, P., \& Haller, M. (1993). Models of reading aloud: Dual route and parallel processing approaches. Psychological Review, 100, 589-608.

Coltheart, M., Masterson, J., Byng, S., Prior, M., \& Riddoch, J. (1983). Surface dyslexia. Quarterly Journal of Experimental Psychology, 35, 469-595.

Coltheart, M., Rastle, K., Perry, C., Langdon, R., \& Ziegler, J. (2001). DRC: A dual route cascaded model of visual word recognition and reading aloud. Psychological Review, 108, 204-256.

Content, A., \& Radeau, M. (1988). Données statistiques sur la structure orthographique du français. Cahiers de Psychologie Cognitive/European Bulletin of Cognitive Psychology. Special issue, 1-87.

Deltour, J.J., \& Hupkens, D. (1980). Test de vocabulaire actif et passif pour enfants (5 à 8 ans). Issyles-Moulineaux: E.A.P.

Dunn, L.M., Thériault-Whalen, C.M., \& Dunn, L.M. (1993). Echelles de vocabulaire en image Peabody. Adaptation française du Peabody Picture Vocabulary Test-Revised. Toronto: Psycan.

Ehri, L.C. (1998). Grapheme-phoneme knowledge is essential for learning to read words in English. In J.L. Metsala, \& L. Ehri (Eds.), Word recognition in beginning literacy (pp. 3-40). Mahwah, NJ: Erlbaum.

Génard, N., Mousty, P., Content, A., Alegria, J., Leybaert, J., \& Morais, J. (1998). Methods to establish subtypes of developmental dyslexia. In P. Reitsma, \& L. Verhoeven (Eds.), Problems and interventions in literacy development (pp. 163-176). Dordrecht: Kluwer.

Grainger, J., Bouttevin, S., Truc, C., Bastien, M., \& Ziegler, J. (2003). Word superiority, pseudoword superiority, and learning to read: A comparison of dyslexic and normal readers. Brain and Language, 87, 432-440.

Hawelka, S., \& Wimmer, H. (2005). Impaired visual processing of multi-element arrays is associated with increased number of eye movements in dyslexic reading. Vision Research, 45, 855-863.

Hurford, D.P., Johnston, M., Nepote, P., Hampton, S., Moore, S., Neal, J., Mueller, A., McGeorge, K., Huff, L., Awad, A., Tatro, C., Juliano, C., \& Huffman, D. (1994). Early identification and remediation of phonological-processing deficits in first-grade children at risk for reading disabilities. Journal of Learning Disabilities, 27, 647-659.

Jimenez-Gonzalez, J.E., \& Ramirez-Santana, G. (2002). Identifying subtypes of reading disability in the Spanish language. The Spanish Journal of Psychology, 5, 3-19.

Jimenez-Gonzalez, J.E., \& Valle, I.H. (2000). Word identification and reading disorders in the Spanish language. Journal of Learning Disabilities, 33, 44-60.

Joanisse, M.F., Manis, F.R., Keating, P., \& Seidenberg, M.S. (2000). Language deficits in dyslexic children: Speech perception, phonology, and morphology. Journal of Experimental Child Psychology, 77, 30-60. 
Landerl, K., \& Wimmer, H. (2000). Deficits in phoneme segmentation are not the core problem of dyslexia: Evidence from German and English children. Applied psycholinguistics, 21, 243-262.

Landerl, K., Wimmer, H., \& Frith, U. (1997). The impact of orthography consistency on dyslexia: A German-English comparison. Cognition, 63, 315-334

Lefavrais, P. (1967). Test de l'Alouette: Manuel. Paris: Les Editions du Centre de Psychologie Appliquée.

Lété, B., Sprenger-Charolles, L., \& Colé, P. (2004). MANULEX: A lexical database from French readers. Behavioral Research Methods, Instruments and Computers, 36, 156-166.

Manis, F.R., Seidenberg, M.S., Doi, L.M., McBride-Chang, C., \& Peterson, A. (1996). On the basis of two subtypes of developmental dyslexia. Cognition, 58, 157-195.

McDougall, P., Borowsky, R., MacKinnon, G.E., \& Hymel, S. (2004). Process dissociation of sight vocabulary and phonetic decoding in reading: A new perspective on surface and phonological dyslexias. Brain and Language, 92, 185-203.

Metsala, J.L., Stanovich, K.E., \& Brown, G.D.A. (1998). Regularity effects and the phonological deficit model of reading disabilities: A meta-analytic review. Journal of Educational Psychology, 90, 279-293.

Milne, R.D., Nicholson, T., \& Corballis, M.C. (2003). Lexical access and phonological decoding in adult dyslexic subtypes. Neuropsychology, 17, 362-368.

Parrila, R., Kirby, J.R., \& McQuarrie, L. (2004). Articulation rate, naming speed, verbal short-term memory and phonological awareness: Longitudinal predictors of early reading development. Scientific Study of Reading, 8, 3-26.

Peereman, R., \& Content, A. (1998). Quantitative analysis of orthography to phonology mapping in English and French (on-line). http://homepages.vub.ac.be/ acontent/OPMapping.html.

Peereman, R., Lété, B., \& Sprenger-Charolles, L. (2007). Manulex-infra: Distributional characteristics of infra-lexical and lexical units in child-directed written material. Behavior Research Methods, Instruments and Computers. 39(3), 593-603.

Pennington, B.F., Cardoso-Martins, C., Green, P., \& Lefly, D.L. (2001). Comparing the phonological and double deficit hypothesis for developmental dyslexia. Reading and Writing: An Interdisciplinary Journal, 14, 707-755.

Rack, J.P., Snowling, M.J., \& Olson, R.K. (1992). The nonword reading deficit in developmental dyslexia: A review. Reading Research Quarterly, 27, 29-53.

Ramus, F., Pidgeon, E., \& Frith, U. (2003). The relationship between motor control and phonology in dyslexic children. Journal of Child Psychology and Psychiatry, 44, 712-722.

RAVEN (1947/1981). Progressive Matrices Standard. Issy-les-Moulineaux: E.A.P.

Seymour, P. H. K. (1986). A cognitive analysis of dyslexia. London: Routledge and Kegan Paul.

Share, D.L. (1995). Phonological recoding and self-teaching: Sine qua non of reading acquisition. Cognition, 55, 151-218.

Siegel, L.S. (1993). Phonological processing deficits in reading as the basis of a reading disability. Developmental Review, 13, 246-257.

Siegel, L.S., \& Ryan, E.B. (1988). Development of grammatical sensitivity, phonological, and shortterm memory skills in normally achieving and learning disabled children. Developmental Psychology, 24, 28-37.

Snowling, M.J. (1981). Phonemics deficits in developmental dyslexia. Psychological Research, 43, 219-234.

Snowling, M.J., Stackhouse, J., \& Rack, J. (1986). Phonological dyslexia and dysgraphia: A developmental analysis. Cognitive Neuropsychology, 3, 309-339.

Sprenger-Charolles, L., Colé, P., Béchennec, D., \& Kipffer-Piquard, A. (2005). French normative data on reading and related skills from EVALEC, a new computarized battery of tests. European Review of Applied Psychology, 55, 157-186.

Sprenger-Charolles, L., Colé, P., Lacert, P., \& Serniclaes, W. (2000). On subtypes of developmental dyslexia: Evidence from processing time and accuracy scores. Canadian Journal of Experimental Psychology, 54, 88-104.

Sprenger-Charolles, L., Colé, P., \& Serniclaes, W. (2006). Reading acquisition and developmental dyslexia. Hove and New-York, Psychology Press (Essays in Developmental Psychology). 
Sprenger-Charolles, L., Siegel, L.S., Béchennec, D, \& Serniclaes, W. (2003). Development of phonological and orthographic processing in reading aloud, in silent reading and in spelling: A four year longitudinal study. Journal of Experimental Child Psychology, 84, 194-217.

Sprenger-Charolles, L., Siegel, L.S., \& Bonnet, P. (1998). Phonological mediation and orthographic factors in reading and spelling. Journal of Experimental Child Psychology, 68, 134-155.

Stanovich, K.E., \& Siegel L.S. (1994). Phenotypic performance profile of children with reading disabilities: A regression-based test of the phonological-core variable-difference model. Journal of Educational Psychology, 86, 24-53.

Stanovich, K.E., Siegel, L.S., \& Gottardo, A. (1997). Converging evidence for phonological and surface subtypes of reading disability. Journal of Educational Psychology, 89, 114-127.

Szeszulski, P.A., \& Manis F.R. (1987). A comparison of word recognition processes in dyslexic and normal readers at two reading-age levels. Journal of Experimental Child Psychology, 44, 364-76.

Valdois, S., Bosse, M.L., Ans, B., Carbonnel, S., Zorman, M., David, D., \& Pellat, J. (2003). Phonological and visual processing deficits can dissociate in developmental dyslexia: Evidence from two case studies. Reading and Writing: An Interdisciplinary Journal, 16, 541-572.

Van Ijzendoorn, M.H., \& Bus, A.G. (1994). Meta-analytic confirmation of the non-word reading deficit in developmental dyslexia. Reading Research Quarterly, 29, 266-275.

Vellutino, F.R., Fletcher, J.M., Snowling, M.J., \& Scanlon, D.M. (2004). Specific reading disability (dyslexia): What we have learned in the past four decades? Journal of Child Psychology and Psychiatry, 45, 2-40.

Vellutino, F.R., Scanlon, D.M., Sipay, E.R., Small, S.G., Pratt, A., Chen, R., \& Denckla, M.B. (1996). Cognitive profiles of difficult-to-remediate and readily remediated poor-readers: Early intervention as a vehicle for distinguishing between cognitive and experiential deficits as basic causes of specific reading disability. Journal of Educational Psychology, 88, 601-638.

Vukovic, R.K., \& Siegel, L.S. (2006). The double deficit hypothesis: A comprehensive analysis of the evidence. Journal of Learning disabilities, 39, 25-47.

Wagner, R.K., Torgesen, J.K., Rashotte, C.A., Hecht, S.A., Barker, T.A., Burgess, S.R., Donahue, J., $\&$ Baron, T. (1997). Changing relations between phonological processing abilities and word-level reading as children develop from beginning to skilled readers: A five year longitudinal study. Developmental Psychology, 33, 468-479.

Waters, G.S., Seidenberg, M.S., \& Bruck, M. (1984). Children's and adults' use of spelling sound information in three reading tasks. Memory \& Cognition, 12, 293-305.

Weekes, B.S. (1997). Differencial effect of number of letters on words and nonwords naming latency. Quarterly Journal of Experimental Psychology, 50A, 439-456.

Wimmer, H. (1993). Characteristics of developmental dyslexia in a regular writing system. Applied Psycholinguistics, 14, 1-33.

Wolf, M., Goldberg O'Rourke, A., Gidney, C., Lovett, M., Cirino, P., \& Morris, R. (2002). The second deficit: An investigation of the independence of phonological and naming-speed deficits in developmental dyslexia. Reading and Writing: An Interdisciplinary Journal, 15, 43-72.

Zabell, C., \& Everatt, J. (2002). Surface and phonological subtypes of adult developmental dyslexia. Dyslexia, 8, 160-177.

Ziegler, J., \& Goswami, U. (2005). Reading acquisition, developmental dyslexia and skilled reading across languages: A psycholinguistic grain size theory. Psychological Bulletin, 131, 3-29.

Ziegler, A., Perry, C., Ma-Wyatt, A., Ladner, D., \& Schulte-Körne, G. (2003). Developmental dyslexia in different languages: Language specific or universal? Journal of Experimental Child Psychology, 86, 169-193. 